Article

\title{
The 40bp Indel Polymorphism rs150550023 in the MDM2 Promoter is Associated with Intriguing Shifts in Gene Expression in the p53-MDM2 Regulatory Hub
}

\author{
Heidi Miedl ${ }^{1}$, Bianca Dietrich ${ }^{1}$ D , Klaus Kaserer ${ }^{2}$ and Martin Schreiber ${ }^{1,3, * \mathbb{D}}$ \\ 1 Department of Obstetrics \& Gynecology, Medical University of Vienna, 1090 Vienna, Austria; \\ heidi.miedl@muv.ac.at (H.M.); bianca.dietrich@muv.ac.at (B.D.) \\ 2 Labor Kaserer, Salzer and Beer, 1030 Vienna, Austria; office@labor-kaserer.at \\ 3 Comprehensive Cancer Center, Medical University of Vienna, 1090 Vienna, Austria \\ * Correspondence: martin.schreiber@muv.ac.at
}

Received: 8 October 2020; Accepted: 11 November 2020; Published: 13 November 2020

Simple Summary: Many naturally occurring variants in the human DNA sequence have an influence on cancer risk, and most of them are located outside the parts of the genome that code for proteins. Presumably, they have an effect on the amount of messenger RNA and protein that is made from genes in their neighborhood. We analyzed one such DNA sequence variant termed rs150550023, which is near a gene termed MDM2 (human homolog of mouse double minute 2). The main function of $M D M 2$ is to negatively regulate another gene termed p53, which is a very important tumor suppressor, i.e., it counteracts cancer. We studied the DNA sequence variant rs 150550023 by comparing it in 407 female patients with breast cancer and 254 females without cancer. We found no evidence that rs150550023 plays an important role in the risk of breast cancer, the average age at which patients get breast cancer, how many patients develop breast cancer metastases, or how many patients die of breast cancer. However, we found evidence that rs150550023 may work together with another DNA sequence variant within the $M D M 2$ gene termed SNP309. We also analyzed the tumor tissue of $\approx 100$ breast cancer patients of this study after it had been surgically removed. We measured the amount of messenger RNA (mRNA) which is made from the genes MDM2, p53, and three other genes (termed p21, BAX, and PERP) for which it is known that p53 has an influence on the amount of their mRNA being made. We found that rs150550023 indeed has an influence on the amount of mRNA made from some of these genes. However, since MDM2 is a negative regulator of p53, it is likely that many of these alterations cancel each other out if both p53 and MDM2 is produced at higher levels.

\begin{abstract}
Most low-penetrance genetic risk factors for cancer are located in noncoding regions, presumably altering the regulation of neighboring genes. The poorly characterized Indel polymorphism rs150550023 (rs3730485; del1518) in the promoter of MDM2 (human homolog of mouse double minute 2) is a biologically plausible candidate genetic risk factor, which might influence the expression of $M D M 2$, a key negative regulator of the central tumor suppressor p53. Here, we genotyped rs150550023 in a Central European hospital-based case-control study of 407 breast cancer patients and 254 female controls. mRNA levels of MDM2, p53, and the p53 target genes p21, BAX, and PERP were quantified with qRT-PCR, and p53 protein was assessed with immune histochemistry in $\approx 100$ primary breast tumors with ascertained rs 150550023 genotype. We found no evidence for an association of rs150550023 with the risk, age at onset, or prognosis of breast cancer. A possible synergism was observed with SNP309 in promoter P2 of MDM2. Mean mRNA levels of MDM2, p53, p21, and BAX were $\approx 1.5-3$ fold elevated in TP53 wildtype tumors with the minor homozygous Del/Del genotype. However, systematic shifts in p53 protein levels or mutation rates were not observed, suggesting that the elevated p53 mRNA levels are due to regulatory feedback loops that compensate for the effects of rs150550023 on MDM2 expression.
\end{abstract}


Keywords: breast cancer; MDM2 (human homolog of mouse double minute 2); rs150550023; rs3730485; Indel polymorphism; mRNA expression; TP53; age at onset; prognosis; tumor tissue

\section{Introduction}

The tumor suppressor gene TP53 is the most commonly mutated gene in human cancer [1,2]. Multiple and diverse stress signals activate p53, mostly by interfering with the negative regulatory activity of MDM2 towards p53 [3,4]. Once activated, p53 initiates a similarly diverse set of responses, resulting in either cell death or repair of the stress-induced damages and maintenance of cellular homeostasis [3-7]. p53 is a transcription factor, and one of its target genes is MDM2, an E3 ubiquitin ligase and key negative regulator of p53 [8-11]. MDM2 targets p53 for proteasomal degradation, and also controls its transcriptional activity, nuclear localization, and rate of translation [10-12]. Thus, by inducing the expression of MDM2, p53 initiates its own degradation, which maintains a short half-life and low levels of the 553 protein in the absence of stress [8].

$M d m 2$ knockout in mice leads to early embryonic lethality, which is rescued by the additional deletion of p53, demonstrating that the key role of MDM2 is to antagonize the function of p53 [13,14]. Aberrant upregulation of MDM2 expression has been observed in many sarcomas and other cancers, resulting in a decrease in the protein level and activity of p53 $[9,10]$. The main mechanisms of this MDM2 activation include amplification of the MDM2 gene and genetic variants in its two promoters P1 and P2 [9,15]. MDM2 amplification and overexpression occurs mostly in a mutually exclusive manner with TP53 mutation, indicating that it may be one important of presumably several mechanisms of aberrant inactivation of p53 function in TP53 wildtype tumors [8,9,16]. Like MDM2 amplification, albeit less pronounced, the G-allele of SNP309 (rs2279744) in MDM2 promoter P2 was also found associated with increased MDM2 expression and a reduced rate of TP53 mutation [17-23]. Moreover, most studies in Asian, but not in Caucasian populations found an association of the G-allele of SNP309 with an increased cancer risk [24-26].

Other studies have indicated an additional potential role in MDM2 expression and cancer risk for an Indel (insertion/deletion) polymorphism located at position -2026_-2025 in the constitutive promoter $\mathrm{P} 1$ region of the $M D M 2$ gene [15,27-29]. Its Ins-allele is characterized by the insertion of the 40bp sequence $(\mathrm{A})_{5}$ GCTGCA(GAAGG) ${ }_{2}$ ATATAACTTTAT $(\mathrm{A})_{7}$, whereas the Del-allele has also one copy (and the Ins-allele hence two copies) of the $3^{\prime} 30 \mathrm{bp}$ of that $40 \mathrm{bp}$ sequence (Figure 1 ). This Indel variant was formerly termed rs3730485 or del1518, but the current official nomenclature according to NCBI Reference SNP (rs) database build 154 is rs150550023, which will be used hereafter. Compared to the extensively studied SNP309 in MDM2 promoter P2, only a few studies have analyzed rs150550023. One study has used reporter assays in HeLa, HepG2, and JEG-3 human cell lines to indicate a role of rs150550023 in promoter P1 activity [15]. All tumor entities combined, fewer than 20 original studies and three meta-analyses have investigated the association of rs150550023 with cancer risk [27-47]. Most of these studies did not find an association, except in specific patient subpopulations, whereas associations with indicators other than cancer risk have hardly been studied for rs150550023. Four studies of breast cancer were reported, two in European and two in Asian populations [30-33]. Two studies reported a considerably increased breast cancer risk associated with the minor Del/Del, but not the Ins/Del genotype [32,33], whereas neither the other two, larger studies nor the meta-analyses found any association of rs150550023 with breast cancer risk [27,29-31]. Several studies have shown a strong linkage disequilibrium between rs150550023 and SNP309 [30,35,41], and one of these studies reported results that indicate a possible synergism between the minor alleles of these two polymorphisms [30]. 
(a) Del-allele

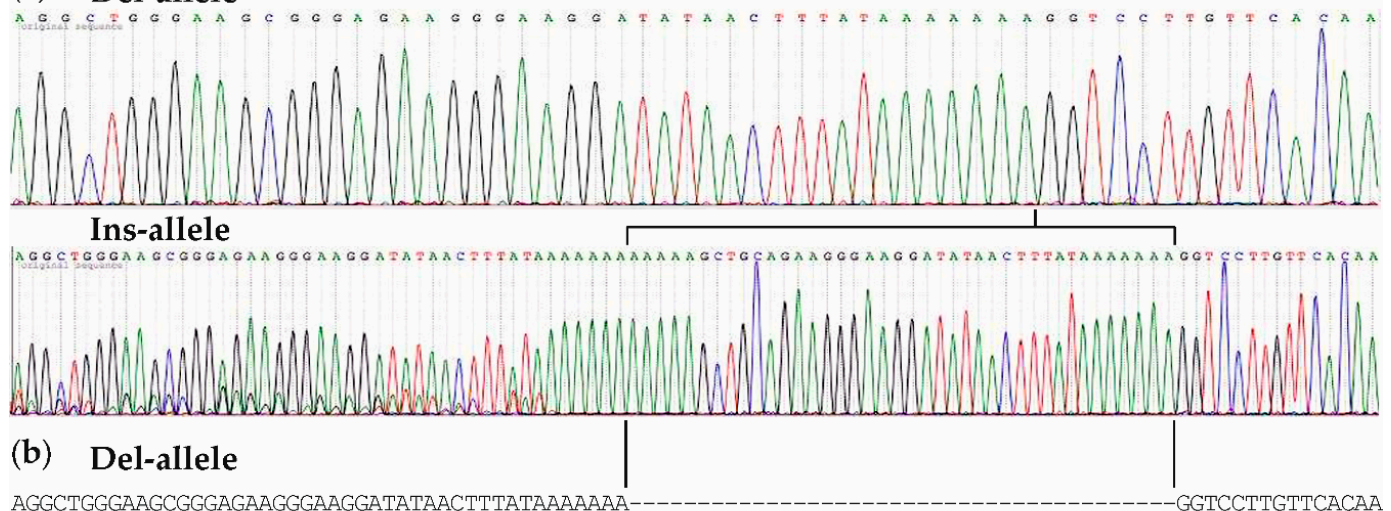

AGGCTGGGAAGCGGGAGAAGGGAAGGATATAACTTTATAAAAAAA

Ins-allele

AGGCTGGGAAGCGGGAGAGGGAAGGATATAACTTTATAAAAAAAAAAAAGCTGCAGAAGGGAAGGATATAACTTTATAAAAAAAGGTCTTGTTCACAA

(c)

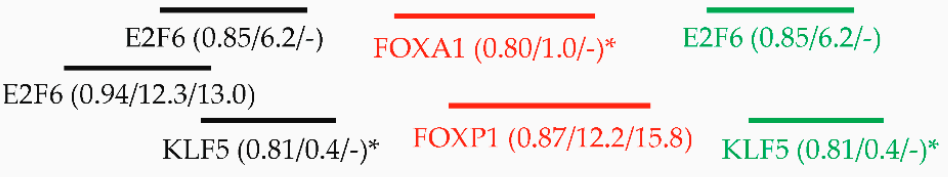

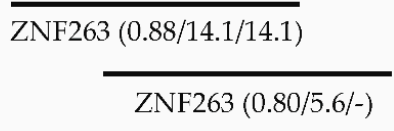

ZNF384

$(1.00 / 16.7 / 17.6)$

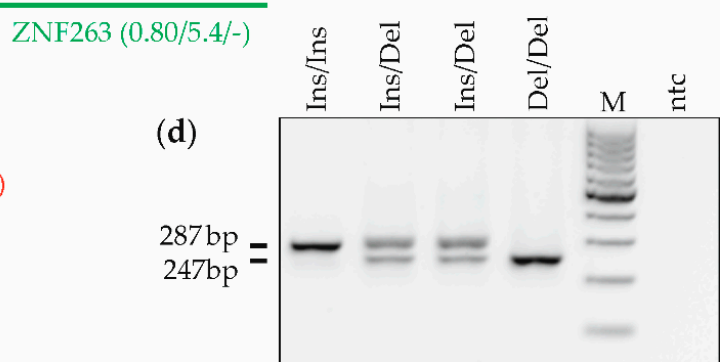

Figure 1. Analysis of the sequence context of MDM2 (human homolog of mouse double minute 2) Indel polymorphism rs150550023. (a) Sequence chromatogram of the relevant genomic region of one representative patient each with the Del/Del and Ins/Ins genotype. (b) Sequence alignment of the Deland the Ins-allele. The 40-bp insertion in the Ins-allele is highlighted in red. Note that an identical 30bp sequence out of these 40bp is also present in the Del-allele (underlined). (c) Predicted transcription factor binding sites in the rs 150550023 Ins-allele (indicated by horizontal lines). Transcription factors binding exclusively to the Ins-allele but not the Del-allele are highlighted in red; extra binding sites within the Ins-allele of transcription factors that bind also to the Del-allele are highlighted in green. Numbers in parentheses indicate relative binding scores in JASPAR analysis/binding scores in JASPAR analysis/binding scores in CIS-BP analysis. * indicates binding to the (-) strand. (d) Genotyping by PCR and agarose gel electrophoresis of four representative samples with the indicated genotypes. The size of PCR-products derived from the Ins-allele (287bp) and the Del-allele (247bp) is indicated. M, DNA length marker, a 100-bp ladder with the 500-bp band present at higher concentration. ntc, nontemplate control (negative control).

SNP309 (rs2279744) is situated in promoter P2 in intron 1 of MDM2, and was shown to affect binding of transcription factor SP1, MDM2 expression, the risk, age at onset, and prognosis of human cancer, as well as p53 levels and the rate of TP53 mutation [17-26]. The rationale of the present study is that rs150550023, which is located in the constitutive promoter P1 proximal to exon1 of MDM2, might have similar biological effects as SNP309. However, most of these potential biological roles of rs150550023 are still poorly characterized, and the main aim of the present study was to venture into some of the "white areas on the rs150550023 map". We analyzed the association of rs150550023 with breast cancer risk, including clinically and biologically relevant subpopulations, with the age at onset, overall and metastasis-free survival, and potential synergism with SNP309. Our main focus was on 
expression analysis of MDM2, p53, and the p53 target genes p21, BAX, and PERP, which was indeed found associated with rs150550023 genotype.

\section{Results}

\subsection{Sequence Analysis and Genotyping of the MDM2 Indel Variant rs150550023}

The sequence of human chromosome 12 containing the MDM2 gene was retrieved from NCBI variation viewer assembly GRCh38.p12 (which contains the major Ins-allele), and the sequence surrounding rs150550023 was visualized in Figure $1 \mathrm{~b}$. We confirmed the sequence in our study population by Sanger sequencing of two randomly selected subjects each with the Ins/Ins and the Del/Del genotype (Figure 1a). The Ins-allele has an insertion of the 40bp sequence (A) $)_{5}$ GCTGCA(GAAGG) ${ }_{2}$ ATATAACTTTAT(A) 7 . A 30bp sequence identical to the $3^{\prime}$ part of this $40 \mathrm{bp}$ insertion is also present in the Del-allele, and is hence duplicated in the Ins-allele (Figure 1). Only the $10 \mathrm{bp}$ at the $5^{\prime}$ end of the $40 \mathrm{bp}$ insertion are unique to the Ins-allele (Figure 1). We note that due to this duplication of 30bp, it is a matter of opinion how to define the last nucleotide of the 40-bp insertion, which can be any of the 30 duplicated nucleotides. Indeed, the insertion was defined as A(GAAGG) ${ }_{2}$ ATATAACTTTAT(A) ${ }_{12}$ GCTGC in the now outdated nomenclature rs 3730485 , a shift by 30 nucleotides compared to the current nomenclature rs150550023.

We next performed in silico analyses of putative transcription factor binding sites around the rs150550023 site, applying JASPAR, CIS-BP, and The Human Protein Atlas databases [48-50]. We found predicted binding sites for FOXA1, FOXP1 (Forkhead Box Proteins A1 and P1) [51,52], and ZNF384 (Zinc Finger Protein 384) [53] unique to the Ins-allele, and binding sites for E2F6 (E2F Transcription Factor 6) [54], KLF5 (Krueppel-like Factor 5) [55], and ZNF263 (Zinc Finger Protein 263) [56] both in the Ins- and the Del-allele, but with one extra binding site each in the Ins-allele (Figure 1c). The highest binding scores could be confirmed with CIS-BP, an independent analysis tool [50]. A previous JASPAR analysis has focused on the breakpoint of the Del-allele (AAAAAAA/GGTCCTT) [30], which, however, is also present in the Ins-allele (Figure 1a,b). In fact, due to the 30-bp duplication there is no sequence that is unique to the Del-allele and absent from the Ins-allele; only sequence unique to the Ins-allele exists (Figure 1a,b). Genotyping was done by PCR and agarose gel electrophoresis. Representative examples of the obtained PCR bands of all three genotypes are shown in Figure 1d.

\subsection{Distribution of rs150550023 Genotypes}

rs150550023 was genotyped in a Central European (Austrian) hospital-based case-control study of 407 breast cancer patients and 254 control subjects. Table S1 shows the clinical and histopathological characteristics as well as the frequency of the rs150550023 genotypes within the study population. The control population $(p=0.72)$ and the breast cancer patient population $(p=0.60)$ were both in Hardy-Weinberg equilibrium for rs150550023. The frequency of the minor Del-allele of rs 150550023 (MAF) was 0.399 in breast cancer patients and 0.429 in controls, close to the 0.416 MAF reported for Europeans by the GnomAD Project population database [57]. We had previously analyzed MDM2 SNP309 (rs2279744) in our study population [21], and found that it was in a strong linkage disequilibrium with rs150550023 $\left(\mathrm{D}^{\prime}=0.925 ; p<0.0001\right)$, consistent with previous reports $[30,35,41]$. Accordingly, the rs150550023 Del-allele was found almost exclusively in a distinct SNP309T/rs150550023-Del haplotype. There were only 10 exceptions in our study population of 659 breast cancer cases and controls, in whom an rs150550023 Del-allele was linked to a SNP309 G-allele (Table S1).

\subsection{MDM2 rs150550023 and Breast Cancer Risk}

Determination of crude and adjusted odds ratios (OR), 95\% confidence intervals (c.i.), and $p$-values revealed no significant associations of rs150550023 genotypes or alleles with breast cancer risk (Table 1), consistent with previous breast cancer studies and meta-analyses [27,29-31]. A previous study of lung, prostate, breast, and colon cancer has found higher odds ratios associated with the rs 150550023 
Del-allele in subjects with the SNP309TG genotype than with the SNP309TT genotype [30]. These findings indicate a possible synergism between the rs150550023 Del-allele and the SNP309 G-allele, even though a significantly increased risk was only found for prostate cancer [30,38].

Table 1. Association of MDM2 rs150550023 genotypes and alleles with breast cancer risk.

\begin{tabular}{lcccccc}
\hline \multirow{2}{*}{ Genotypes/Alleles } & \multicolumn{3}{c}{ Unadjusted } & \multicolumn{3}{c}{ Adjusted for SNP309 and Age } \\
\cline { 2 - 7 } & OR & $\mathbf{9 5 \%}$ c.i. & $p$-Value & OR & $\mathbf{9 5 \%}$ c.i. & $p$-Value \\
\hline Del/Del vs. Ins/Ins & 0.78 & $0.48-1.24$ & 0.289 & 0.68 & $0.36-1.27$ & 0.198 \\
Del/Del vs. Ins/Del & 0.88 & $0.56-1.37$ & 0.564 & 0.91 & $0.51-1.61$ & 0.732 \\
Del/Del vs. Ins/Del + Ins/Ins & 0.83 & $0.55-1.27$ & 0.401 & 0.78 & $0.46-1.34$ & 0.371 \\
Ins/Del vs. Ins/Ins & 0.88 & $0.62-1.25$ & 0.488 & 0.82 & $0.52-1.29$ & 0.353 \\
Ins/Del + Del/Del vs. Ins/Ins & 0.86 & $0.61-1.19$ & 0.356 & 0.80 & $0.51-1.23$ & 0.304 \\
Del vs. Ins & 0.88 & $0.70-1.11$ & 0.276 & 0.82 & $0.60-1.12$ & 0.215 \\
\hline
\end{tabular}

Analyses of all breast cancer cases vs. controls of the indicated genotypes or alleles are shown, unadjusted or adjusted for SNP309 genotype and age as indicated. OR, odds ratio; 95\% c.i., 95\% confidence interval.

Accordingly, we next determined ORs and confidence intervals in SNP309TT and SNP309TG subjects, as well as ORs and confidence intervals adjusted for SNP309 and age (Tables 1 and 2). Due to the strong linkage disequilibrium between rs150550023 and SNP309, SNP309GG subjects are almost exclusively of the rs150550023 Ins/Ins genotype (see Section 2.2), precluding an analogous analysis in this subpopulation. Consistent with a previous breast cancer study [30], we found considerably, but non-significantly elevated odds ratios associated with the Del-allele in SNP309TG subjects compared to SNP309TT subjects (Table 2).

Table 2. Association of MDM2 rs150550023 genotypes and alleles with breast cancer risk in subpopulations according to SNP309 genotype.

\begin{tabular}{lcccccc}
\hline \multirow{2}{*}{ Genotypes/Alleles } & \multicolumn{3}{c}{ in SNP309TT Subjects } & \multicolumn{3}{c}{ in SNP309TG Subjects } \\
\cline { 2 - 7 } & OR & $\mathbf{9 5 \%}$ c.i. & $p$-Value & OR & 95\% c.i. & $p$-Value \\
\hline Del/Del vs. Ins/Ins & 0.56 & $0.26-1.23$ & 0.145 & $2.11^{1}$ & $0.21-21.0$ & 0.501 \\
Del/Del vs. Ins/Del & 0.79 & $0.47-1.33$ & 0.376 & $2.04^{1}$ & $0.21-20.0$ & 0.524 \\
Del/Del vs. Ins/Del + Ins/Ins & 0.73 & $0.44-1.20$ & 0.221 & $2.06^{1}$ & $0.21-20.0$ & 0.513 \\
Ins/Del vs. Ins/Ins & 0.72 & $0.33-1.54$ & 0.388 & 1.04 & $0.64-1.70$ & 0.863 \\
Ins/Del + Del/Del vs. Ins/Ins & 0.65 & $0.31-1.33$ & 0.227 & 1.06 & $0.65-1.72$ & 0.821 \\
Del vs. Ins & 0.76 & $0.53-1.10$ & 0.137 & 1.09 & $0.69-1.73$ & 0.718 \\
\hline
\end{tabular}

Analyses of breast cancer cases vs. controls of the indicated genotypes or alleles are shown. Analyses were performed in the subgroup of breast cancer patients and controls with the SNP309TT genotype, or with the SNP309TG genotype as indicated. OR, odds ratio; $95 \%$ c.i., $95 \%$ confidence interval. ${ }^{1}$ Note that only three patients and one control have the genotype rs150550023 Del/Del-SNP309TG (see Section 2.2).

\subsection{Exploratory Analysis of MDM2 rs150550023 and Breast Cancer Risk in Subpopulations}

The potential association of rs150550023 with breast cancer risk in clinically and histo-pathologically relevant subpopulations has not been thoroughly investigated so far [30-33]. In contrast, associations with the age at onset, estrogen receptor (ER) status, p53 status, and Ki67-status have been demonstrated for SNP309 [17,18,21,58-60]. Accordingly, we explored whether associations of rs150550023 with breast cancer risk in these and other clinically relevant subpopulations exist, and determined ORs in the recessive genetic model (Del/Del vs. Ins/Ins + Ins/Del). This analysis revealed considerable differences in the odds ratios in subgroups stratified by tumor size (pT1 vs. pT2-4), stage (0-1 vs. 2-4), grade (pG1-2 vs. pG3), progesterone receptor (PR) status, Ki67 status ( $\leq 10 \%$ vs. $>10 \%$ Ki67-positive tumor cells), and p53 status (Figure 2). Moreover, odds ratios tended to be lower in subgroups associated with advanced disease and a poor prognosis, such as pT2-4, stage 2-4, pG3 tumors with a negative estrogen and progesterone status and a positive HER2 and p53 status (Figure 2). However, only two of these 
associations were marginally significant: in high grade (pG3) tumors (OR, 0.54 ; 95\% c.i., $0.29-1.00$; $p=0.042)$, and in PR negative tumors (OR, $0.58 ; 95 \%$ c.i., $0.33-1.01 ; p<0.05$; Figure 2).

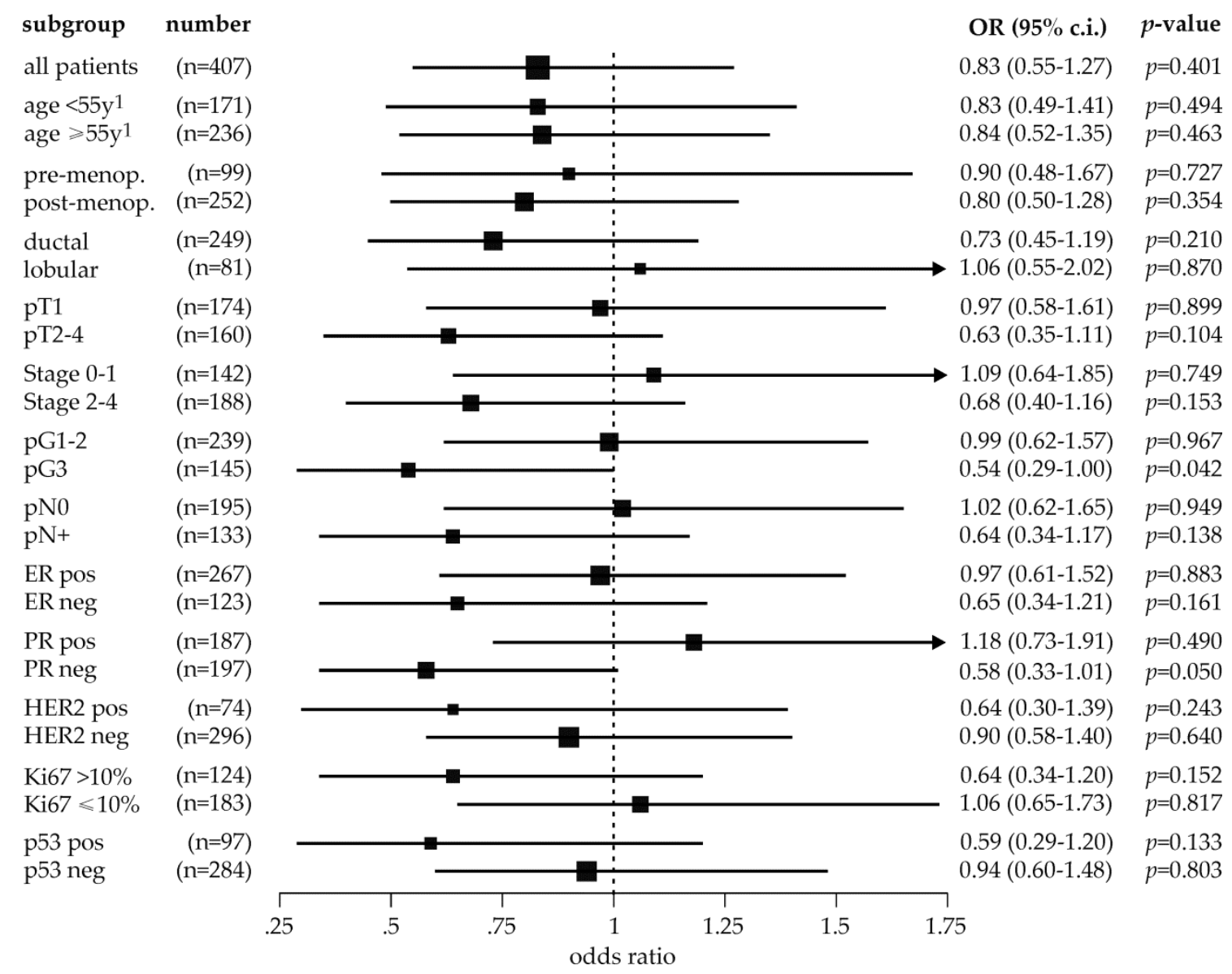

Figure 2. Forest plot illustrating the association of $M D M 2$ polymorphism rs 150550023 with breast cancer risk in the indicated clinical and histopathological patient subpopulations in the recessive genetic model (Del/Del vs. Ins/Ins + Ins/Del). Squares indicate the odds ratios, their expanse the size of the subpopulations (also shown to the left), and horizontal lines the $95 \%$ confidence intervals. Odds ratios (OR), 95\% confidence intervals (95\% c.i.), and $p$-values $(p)$ are in addition shown to the right. menop, menopausal; ER, estrogen receptor; PR, progesterone receptor; pos, positive; neg, negative; ${ }^{1}$ patients aged under 55 years or $\geq 55$ years at diagnosis were compared to control subjects of any age.

\subsection{Association of MDM2 rs150550023 with the Age at Breast Cancer Onset}

MDM2 SNP309 was found associated with the onset age of breast cancer in several studies $[18,21,58,60]$. Since SNP309 is in strong linkage disequilibrium with rs150550023, its association with the age at onset was also investigated. We found the following mean ages of breast cancer onset for patients with the three rs150550023 genotypes: Ins/Ins, $57.7 \pm 14.7$ years (median, 58.6); Ins/Del, $58.6 \pm 13.1$ years (median, 59.3); Del/Del, $57.7 \pm 12.8$ years (median, 58.2; $p \sim 0.8$, ANOVA; Figure 3a). 

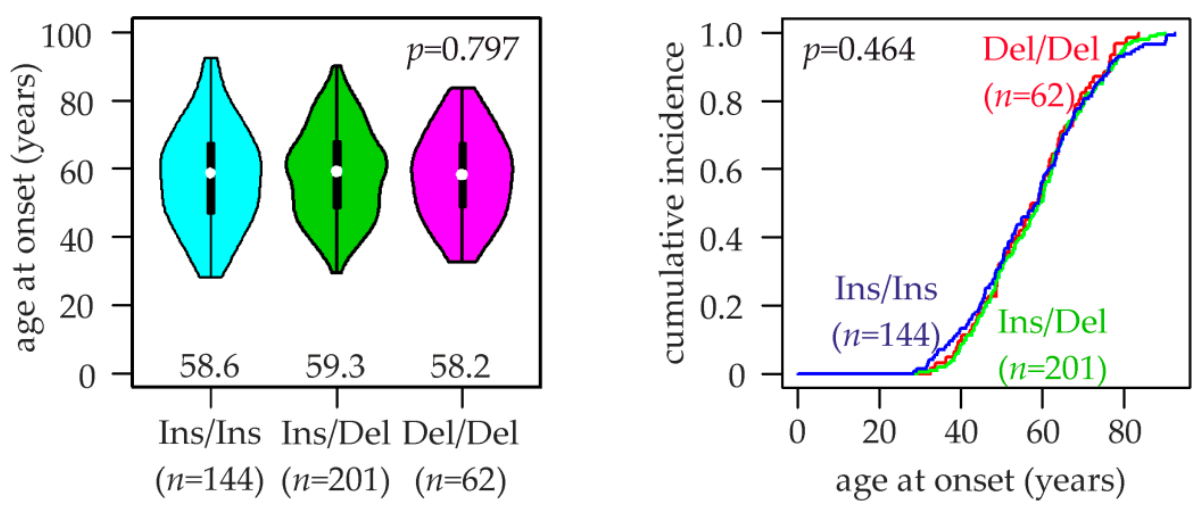

(a) all patients
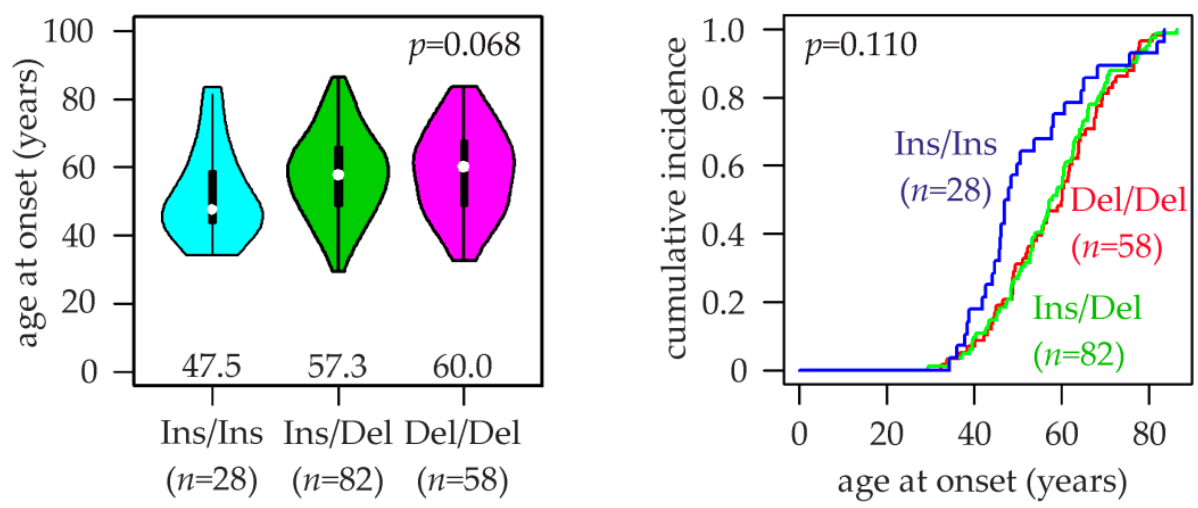

(b) SNP309 TT patients

Figure 3. Association of rs150550023 genotypes with the age at breast cancer onset. Violin plots (left) and curves of the cumulative breast cancer incidence (right) of the indicated age at onset are shown for (a) all patients of the study population, and (b) patients with the SNP309TT genotype. rs150550023 genotypes (Ins/Ins, Ins/Del, Del/Del) and numbers of patients $(n)$ are indicated. Numbers in left panels represent the median age at breast cancer onset of each genotype (indicated by white dots). $p$-values $(p)$ in left panels were calculated with ANOVA, and in right panels with log-rank tests.

In carriers of the SNP309TT genotype, this analysis revealed pronounced differences in the age at onset: Ins/Ins, $52.1 \pm 13.3$ years (median, 47.5); Ins/Del, $57.9 \pm 12.4$ years (median, 57.6); Del/Del, $58.5 \pm 12.7$ years (median, 60.0; $p \sim 0.07$, ANOVA; Figure 3b). Thus, patients with the Ins/Ins genotype exhibited an 11.4 years younger median age at breast cancer onset than carriers of the Del-allele (47.5 vs. 58.9 years; $p=0.032$, unpaired two-sided $t$-test) in the SNP309TT subpopulation. The curve of cumulative breast cancer incidence of Ins/Ins patients appeared biphasic, with a considerably steeper slope than Del-allele carriers up to an age of approximately 51 years, and a gentler incline thereafter (Figure 3b). This age roughly coincides with menopause. This biphasic increase in the cumulative incidence in Ins/Ins-SNP309TT patients also results in the median being off-center in the violin plots, and being considerably smaller than the mean (Figure $3 b$ ). 


\subsection{MDM2 rs150550023 and mRNA Levels of MDM2, p53, and p53 Target Genes}

In silico analysis has indicated differential binding of transcriptional repressors and activators to the Ins vs. Del alleles of rs150550023, which is located in the constitutive promoter P1 of MDM2 (see Section 2.1). Accordingly, we applied qRT-PCR to quantify the expression of MDM2 mRNA in $\approx 100$ human breast tumor samples as well as in 16 breast cancer and four untransformed mammary epithelial cell lines with predetermined rs150550023 genotypes (Figure 4). The expression of p53 itself, and of the p53 target genes BAX [61], PERP [62], and p21 (CDKN1A) [63] was analyzed in parallel. As expected, the mean expression of p53 target genes was higher in wildtype TP53 tumors compared to tumors with a mutated TP53 (as determined by sequencing; Appendix A): MDM2, 1.5-fold higher ( $p=0.07$; unpaired, two-sided $t$-test); BAX, 1.4-fold higher $(p=0.08)$; 21 , 2.3-fold higher $(p=0.0001)$. Thus, p53 status had a comparably modest effect on BAX expression, consistent with findings in p53 null hematopoietic cells [7,64]. Although PERP expression can be potently induced by p53 [65], we found virtually no effect of p53 status on steady-state PERP mRNA levels (0.94-fold change; $p=0.77$ ), as reported previously [66]. Mean mRNA levels of p53 itself were 1.23-fold elevated in TP53 wildtype tumors $(p=0.4)$, consistent with the finding that p53 can bind to and activate its own promoter [64,67].

MDM2 is a p53 target gene and engaged in a negative regulatory feedback loop with p53. Thus, we expected a more direct, proportionally larger impact of rs150550023 genotype on MDM2 expression in tumors with a mutated TP53 gene, in which the additional, potentially confounding effects of p53 on MDM2 expression are absent. In the TP53 wildtype background, MDM2 expression in Ins/Del tumors was higher than in Ins/Ins tumors, but comparable to Del/Del tumors (Ins/Del + Del/Del vs. Ins/Ins tumors: 1.5-fold up, $p=0.18$; Figure 4). In the TP53 mutated background, MDM2 expression in Ins/Del tumors was also higher than in Ins/Ins tumors, but was further elevated in Del/Del tumors (2-fold; $p=0.12$ ). In contrast to MDM2, any effect of rs150550023 genotype on other p53 target genes is expected to be indirect, via p53. Indeed, BAX, PERP, and p21 expression was virtually unaffected by rs150550023 genotype in tumors with mutated TP53 $(p=0.862, p=0.832$ and $p=0.931$, respectively; ANOVA; Figure 4). In TP53 wildtype tumors, BAX, PERP, and p21 roughly reproduced the expression pattern of MDM2: approximately equal expression levels in Ins/Del and Del/Del tumors, which were both higher than those in Ins/Ins tumors (Figure 4). The following relative expression levels of Ins/Del + Del/Del vs. Ins/Ins tumors were observed: BAX, 1.5-fold higher $(p=0.07) ;$ PERP, 2.7-fold higher $(p=0.002)$; $21,1.8$-fold higher $(p=0.02)$. Interestingly, p53 mRNA levels associated with the Ins/Del genotype were also higher compared to Ins/Ins (2.4-fold, $p=0.004)$, and were further elevated in the Del/Del genotype (1.5-fold, $p=0.04$ ) in TP53 wildtype, but not TP53 mutant tumors (Figure 4). The expression patterns in cell lines were very similar to those in TP53 wildtype tumors for all genes analyzed (Figure 4).

Next, we analyzed the combined effects on MDM2 mRNA expression of rs150550023 genotype and p53 status as well as estrogen receptor (ER) status (Figure 5). Mean and median MDM2 levels of tumors with a mutated TP53 were clearly lower than in TP53 wildtype tumors in patients with the Ins/Ins genotype (mean, $1.2 \times$ lower; median, $2 \times$ lower; $p=0.69$; unpaired, two-sided $t$-test) and the Ins/Del genotype (mean, $2 \times$ lower; median, $2.4 \times$ lower; $p=0.047$ ), but were only slightly reduced in patients with the Del/Del genotype (mean, 1.16× lower; median, $1.04 \times$ lower; $p=0.69$; Figure 5a). 


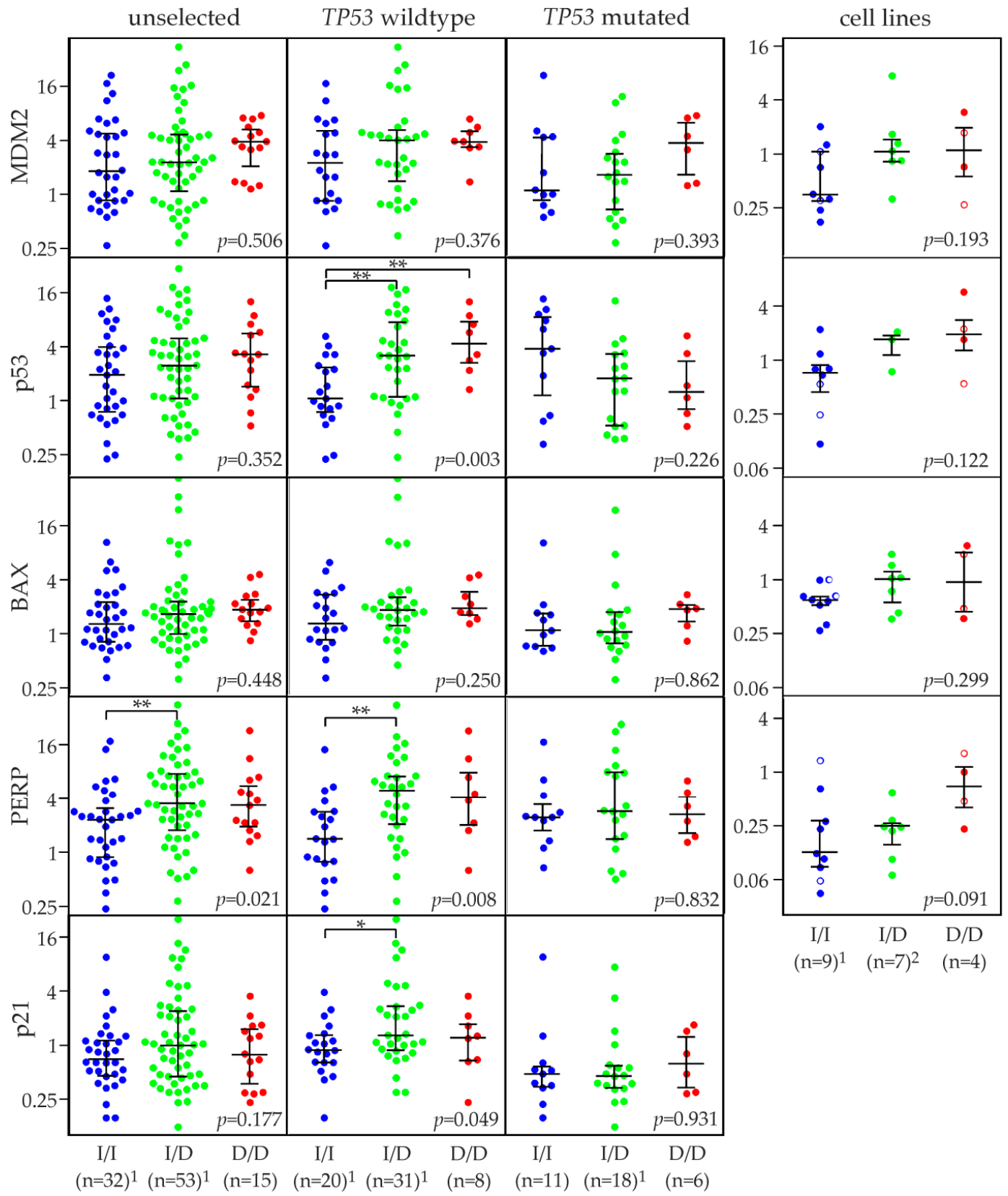

Figure 4. Association of rs150550023 genotypes with the expression of p53 target genes in human breast cancer. Strip charts of MDM2, p53, BAX, PERP, and p21 relative mRNA levels of breast tumors and cell lines, normalized to B-actin. Results for unselected patients, patients with wildtype TP53, patients with mutated TP53, and breast cancer plus untransformed mammary epithelial cell lines (the latter indicated with open circles) are shown. Genotypes (Ins/Ins [I/I], Ins/Del [I/D], Del/Del [D/D]) and numbers of patients (n) are indicated. Horizontal lines indicate the first, second (i.e., median), and third quartiles. All $p$-values $(p)$ indicated were calculated with ANOVA. Note that y-axes are logarithmic $(\log [2]) .{ }^{1}$ The number of patients and cell lines is 1-2 lower than indicated in some of the panels due to unsuccessful qRT-PCR in some samples. ${ }^{2}$ Expression of p53 was successfully determined in three instead of seven cell lines with genotype Ins/Del. ${ }^{*} p<0.05 ;{ }^{* *} p<0.01$ in comparisons of two groups; unpaired, two-sided $t$-tests. 
a

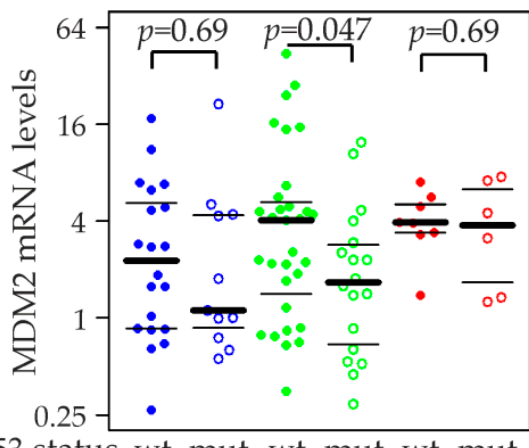

p53 status wt mut wt mut wt mut

$$
\frac{(20)(11)}{\text { Ins/Ins }} \underset{\text { Ins/Del }}{(31)(18)} \frac{(8) \quad(6)}{\text { Del/Del }}
$$

b

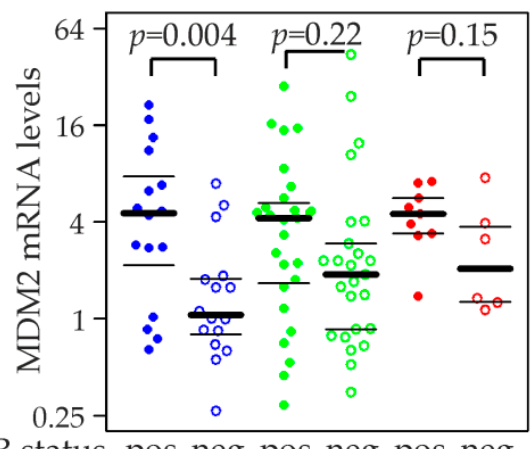

ER status pos neg pos neg pos neg

$$
\underset{\text { Ins/Ins }}{(16)(16)} \underset{\text { Ins/Del }}{(27)}(25) \frac{(9) \quad(6)}{\text { Del/Del }}
$$

C Spearman's correlation

$$
\begin{array}{cl}
\text { All } & \mathrm{r}=0.57, p=7.3 \times 10^{-10} \\
\text { - Ins/Ins } & \mathrm{r}=0.61, p=0.0002 \\
\text { - Ins/Del } & \mathrm{r}=0.58, p=6.7 \times 10^{-6} \\
\text { - Del/Del } & \mathrm{r}=0.33, p=0.232
\end{array}
$$

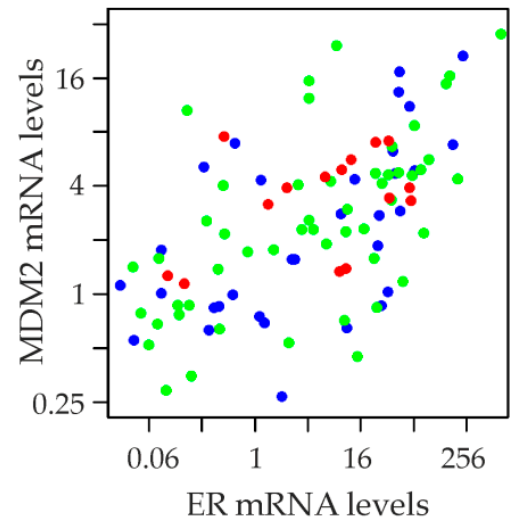

Figure 5. Association of rs150550023 genotypes with MDM2 mRNA expression, p53 status, and ER status in human primary breast tumors. rs150550023 genotypes and numbers of patients are indicated underneath each group. Relative MDM2 and ER (ESR1; estrogen receptor) mRNA levels, normalized to B-actin, are shown on a logarithmic ( $\log [2])$ scale. (a) MDM2 mRNA expression in six groups of breast tumors stratified by rs150550023 genotype and p53 status (wt, wildtype; filled circles, and mut, mutated; open circles). (b) MDM2 mRNA expression in six groups of breast tumors stratified by rs150550023 genotype and ER status (pos, positive; filled circles, and neg, negative; open circles). (c) Correlation between MDM2 and ESR1 (ER) mRNA expression. Spearman's rho (rank correlation coefficients) and corresponding $p$-values are indicated for all patients, and separately for each rs150550023 genotype (visualized by the indicated color code). $(\mathbf{a}, \mathbf{b}) p$-values $(p)$ indicated were determined with unpaired, two-sided $t$-tests. Horizontal lines indicate the first, second (i.e., median), and third quartiles.

Like p53, the estrogen receptor (ER) binds to and activates MDM2 promoter P2 [59,68,69], and we found a similar expression pattern in ER positive vs. negative tumors. Ins/Ins: mean, $3 \times$ lower in ER neg than ER pos tumors; median, $4.3 \times$ lower; $p=0.004$; Ins/Del: mean, $1.5 \times$ lower; median, $2.2 \times$ lower; $p=0.22$; Del/Del: mean, $1.7 \times$ lower; median, $2.2 \times$ lower; $p=0.15$ (Figure $5 b$ ). From a different perspective, rs150550023 genotype had an impact on MDM2 expression only in ER negative tumors, whereas MDM2 levels of the three genotypes were very similar in ER positive tumors (Figure $5 b$ ). Similarly, the effect of rs 150550023 genotype on MDM2 expression was much stronger in tumors with a mutated TP53 than in TP53 wildtype tumors (Figure 5a). We further analyzed the correlation of MDM2 and ESR1 (ER) mRNA levels using Spearman's rank correlation and scatterplots for visualization (Figure 5c). A strong positive correlation was observed in the study population of 110 tumors $(\rho=0.57$; $\left.p=7 \times 10^{-10}\right)$. The more Ins-alleles that were present, the stronger the correlation observed, as demonstrated by higher values obtained for Spearman's rho ( $\rho$ ): Ins/Ins, $\rho=0.61, p=0.0002$; Ins/Del, $\rho=0.58, p=7 \times 10^{-6} ; \mathrm{Del} / \mathrm{Del}, \rho=0.33 ; p=0.23$ (Figure 5c). 


\subsection{Association of MDM2 rs150550023 with Expression of p53 Protein}

We next found a strong positive correlation between MDM2 and p53 mRNA in TP53 wildtype tumors (Spearman's rank correlation coefficient $\rho=0.65, p=6 \times 10^{-8}$; Figure 6a), but a much weaker one in tumors with mutated TP53 ( $\rho=0.4, p=0.02$; data not shown). Within the TP53 wildtype subtype, the weakest correlation was found in Ins/Ins tumors $(\rho=0.5, p=0.03)$, compared to Ins/Del $(\rho=0.66$, $\left.p=9 \times 10^{-5}\right)$ and Del/Del tumors $(\rho=0.69, p=0.07$; Figure 6a). On average, Del/Del tumors had higher levels of both MDM2 and p53 mRNA than Ins/Ins tumors. Specifically, the p53 mRNA levels of half of the Del/Del tumors were higher than the maximum level of Ins/Ins tumors (Figure 6a; see also Figure 4). Moreover, the range of mRNA levels of both MDM2 and p53 was considerably narrower in Del/Del than in Ins/Ins and Ins/Del tumors. For example, the difference between the highest and lowest MDM2 levels was 41-fold in Ins/Ins tumors, but only 5-fold in Del/Del tumors (Figure 6a). We next analyzed the correlation of p53 mRNA and protein as a function of rs150550023 genotype (Figure 6b). Immune histochemistry (IHC) revealed that most tumors with a mutated TP53 gene exhibited well above 20\% p53 positive cells (Figure $6 \mathrm{~b}, \mathrm{c}$ ), most likely because those mutant p53 proteins have lost the ability to activate MDM2 and other regulatory feedback loops (Appendix A).
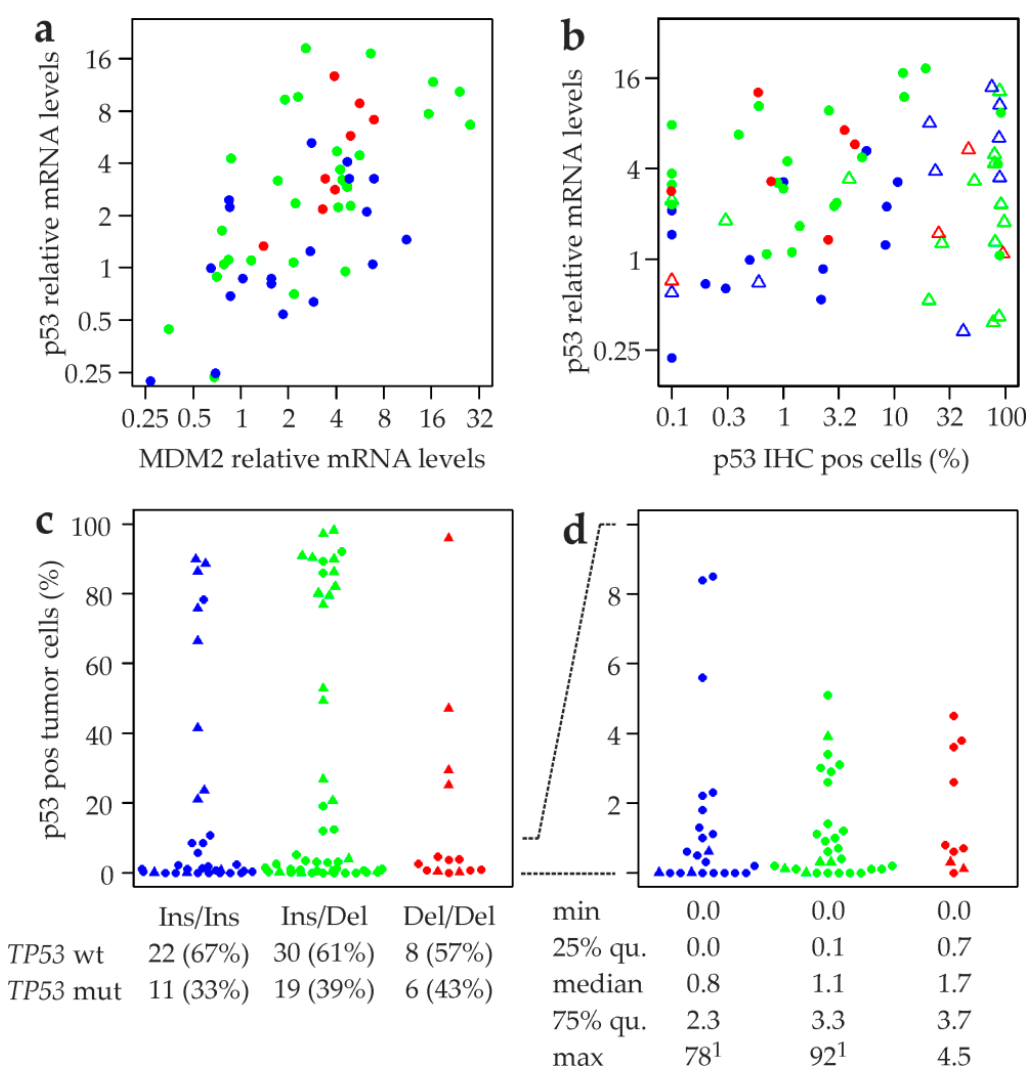

Figure 6. Association of rs150550023 genotypes with p53 protein in human primary breast tumors. (a) Correlation between MDM2 and p53 mRNA expression. (b) Correlation between p53 mRNA and protein expression. p53 positive tumor cells (\%) were determined by immune histochemistry in breast tumors with the indicated rs150550023 genotype and TP53 status. (c) p53 positive tumor cells (\%) in breast tumors with the three indicated rs150550023 genotypes and TP53 status. The numbers and frequencies (\%) of the patients with a wildtype and mutated p53 are indicated underneath each group. (d) The part of panel (c) with 0-10\% p53 positive tumor cells is shown. Numbers underneath indicate the minimum, median, maximum, $25 \%$ and $75 \%$ quantiles (qu.) of p53 positive tumor cells (\%) for each rs150550023 genotype, considering only tumors with a wildtype TP53. rs150550023 genotypes are color coded as follows: Ins/Ins, blue; Ins/Del, green; Del/Del, red. TP53 status is indicated as follows: wildtype (wt), circles; mutated (mut), triangles. ${ }^{1}$ represented in panel (c) only. 
The rate of TP53 mutation was non-significantly elevated in Del/Del tumors, which was, however, not confirmed by p53 IHC status of the complete study population (Figure 6c; Table S1). Since p53 protein levels in tumors with a mutated TP53 are thus not the result of physiological regulation, we focused our analysis on TP53 wildtype tumors, in which we found a marginally significant positive correlation between p53 mRNA levels and p53 IHC positive cells $(\rho=0.3, p=0.05$; Figure $6 \mathrm{~b})$. This correlation was strongest in Ins/Ins tumors $(\rho=0.46, p=0.1)$, weaker in Ins/Del tumors $(\rho=0.19$, $p=0.4$; Figure $6 \mathrm{~b})$, and weakest in Del/Del tumors $(\rho=0.14, p=0.8$; Figure $6 \mathrm{~b})$. In this TP53 wildtype subpopulation, we found that Del/Del tumors exhibit considerably higher average p53 mRNA levels than Ins/Ins tumors, but without a correspondingly higher number of p53 protein positive cells (Figure 6b). Thus, Del/Del tumors appear to require higher levels of p53 mRNA to attain comparable levels of p53 protein. Like p53 and MDM2 mRNA levels, the number of p53 positive cells was in a narrower range in Del/Del tumors compared to Ins/Ins and Ins/Del tumors (Figure 6b-d). TP53 wildtype Del/Del tumors had a maximum of 4.5\% p53 positive cells; all tumors with a higher fraction had a mutated TP53 (Figure 6c,d). Whereas the majority of Ins/Ins and Ins/Del tumors with $>10 \%$ p53 positive cells also had a mutated TP53 gene, we observed 2/22 tumors with wildtype TP53 and $>10 \%$ p53 positive cells in Ins/Ins tumors (maximum, 78\%), and 6/30 Ins/Del tumors (maximum, $92 \%$; Figure $6 \mathrm{c}, \mathrm{d})$. On the other hand, we also found a large fraction of tumors with the Ins/Ins and Ins/Del genotype with no or almost no p53 positive cells, which was not observed in Del/Del tumors (Figure 6d). In spite of the lower maximum of p53 positive cells in Del/Del tumors, the median, 25\% and $75 \%$ quantiles were actually highest in Del/Del tumors and lowest in Ins/Ins tumors (Figure 6d).

\subsection{Association of MDM2 rs150550023 with Breast Cancer Prognosis}

The overall survival (OS) and metastasis-free survival (MFS) of the three MDM2 rs150550023 genotypes was compared in univariable and multivariable Cox proportional hazards analyses of 134 patients treated between 1991 and 1994, for whom detailed follow-up records were available (Tables 3 and 4). The status of p53, ER, and PR as well as SNP309 genotype were included as additional variables in this analysis. No evidence for an association of rs150550023 genotype with breast cancer prognosis was found in any of these analyses. Curiously, Kaplan-Meier analyses revealed a significant association of the Ins/Ins genotype with a poor survival free of metastases to distant lymph nodes in patients with the SNP309TT genotype $(p=0.01)$, with ER negative tumors $(p=0.006)$, and with a mutated TP53 $(p=0.03$; data not shown). In contrast, no association was found in the analyses of the survival free of metastases to the liver, lung, bone, brain, and pleura (data not shown).

Table 3. Univariable and multivariable analyses of the overall survival using a Cox proportional hazards model.

\begin{tabular}{lcccccc}
\hline \multirow{2}{*}{ Variable } & \multicolumn{3}{c}{ Univariable } & \multicolumn{3}{c}{ Multivariable } \\
\cline { 2 - 7 } & HR & $\mathbf{9 5 \%}$ c.i. & $\boldsymbol{p}$-Value & HR & $\mathbf{9 5 \%}$ c.i. & $p$-Value \\
\hline rs150550023 & 0.96 & $0.68-1.36$ & 0.821 & 0.92 & $0.64-1.33$ & 0.668 \\
SNP309 & 1.05 & $0.76-1.46$ & 0.768 & 1.03 & $0.71-1.49$ & 0.874 \\
p53 status & 1.36 & $0.84-2.19$ & 0.204 & 1.08 & $0.64-1.84$ & 0.768 \\
ER status & 1.32 & $0.84-2.06$ & 0.228 & 1.17 & $0.71-1.95$ & 0.532 \\
PR status & 1.45 & $0.91-2.30$ & 0.117 & 1.45 & $0.86-2.45$ & 0.163 \\
\hline
\end{tabular}

HR, hazard ratio; $95 \%$ c.i., $95 \%$ confidence intervals; ER, estrogen receptor. Subcategories of the indicated variables were coded as described in Methods. 
Table 4. Univariable and multivariable analyses of the metastasis-free survival using a Cox proportional hazards model.

\begin{tabular}{lcccccc}
\hline \multirow{2}{*}{ Variable } & \multicolumn{3}{c}{ Univariable } & \multicolumn{3}{c}{ Multivariable } \\
\cline { 2 - 7 } & HR & $\mathbf{9 5 \%}$ c.i. & $p$-Value & HR & $\mathbf{9 5 \%}$ c.i. & $p$-Value \\
\hline rs150550023 & 1.10 & $0.75-1.62$ & 0.624 & 0.96 & $0.64-1.45$ & 0.859 \\
SNP309 & 0.80 & $0.54-1.18$ & 0.266 & 0.77 & $0.50-1.18$ & 0.231 \\
p53 status & 1.55 & $0.93-2.60$ & 0.094 & 1.12 & $0.64-1.98$ & 0.689 \\
ER status & 1.41 & $0.87-2.30$ & 0.167 & 1.17 & $0.68-2.02$ & 0.565 \\
PR status & 1.65 & $0.98-2.77$ & 0.057 & 1.65 & $0.91-3.00$ & 0.097 \\
\hline
\end{tabular}

HR, hazard ratio; 95\% c.i., 95\% confidence intervals; ER, estrogen receptor; PR, progesteron receptor. Subcategories of the indicated variables were coded as described in Methods.

\section{Discussion}

Here we report a comprehensive analysis of the rs150550023 Indel polymorphism located in the constitutive promoter P1 of the human MDM2 gene, including the first investigation of rs150550023 association with the age at onset and prognosis of any cancer, and with the mRNA expression of MDM2 and other relevant genes in tumor tissue. We did not find an association of rs150550023 with breast cancer risk, in agreement with most previous studies and meta-analyses [27-47]. The reports of a nonsignificantly elevated vs. a nonsignificantly reduced risk associated with the Del-allele (like in the present study) are divided roughly equally. However, in those few studies reporting a significant association, the Del-allele was associated with an increased risk [30,32,33,39]. On the other hand, a significantly reduced risk associated with the Del-allele was found in carriers of the SNP309TT genotype for endometrial cancer in the recessive and dominant model [38]. This modifier effect of SNP309 upon the cancer risk associated with rs150550023 was significant only in endometrial cancer, but a nonsignificant trend was also observed in ovarian cancer, colon cancer, lung cancer in females, and breast cancer, in agreement with the present study $[30,38]$. In all cases, odds ratios associated with the Del-allele were considerably lower in carriers of the SNP309TT genotype than in carriers of the SNP309TG genotype. These two subpopulations differ with respect to the presence of the SNP309 G-allele, indicating a functional synergism between the SNP309 G-allele and the rs150550023 Del-allele (and/or vice versa, between the SNP309 T-allele and the rs150550023 Ins-allele) [30,38]. In addition to cancer risk, this potential synergism manifested in the age of breast cancer onset in the present study, which was $\approx 10$ years earlier in patients with the Ins/Ins genotype than in carriers of the Del-allele in the SNP309TT subpopulation, but not in unselected patients.

We also determined ORs in the recessive genetic model in various clinically and molecularly relevant breast cancer subpopulations. This analysis revealed that odds ratios tended to be lower in subgroups associated with advanced disease and a poor prognosis, such as pT2-4, stage 2-4, pG3, ER and PR negative, as well as HER2 and p53 positive. Thus, the Del/Del genotype was less frequent in those subgroups of advanced disease than in the corresponding subgroups with a good prognosis (e.g., pT1, stage 0-1; Table S1; Figure 2), indicating that Del/Del patients are more likely than Ins-carriers to develop a less aggressive form of breast cancer. Nevertheless, no association of rs150550023 with breast cancer prognosis was detected in our survival analysis.

In a collection of $\approx 100$ primary human breast tumors, we extensively analyzed the association of rs150550023 genotype with the mRNA levels of MDM2, p53, and three additional p53 target genes, as well as p53 protein expression and the mutual interdependencies of these expression levels. Our major findings are as follows: (i) mean and median MDM2 mRNA levels were $\approx 1.5-2$-fold higher in Del/Del than Ins/Ins tumors, and this difference was more pronounced in tumors with a mutated TP53 than in wildtype TP53 tumors. This is likely due to confounding effects of wildtype p53, which also increases MDM2 levels, but independently of rs150550023. (ii) The mRNA levels of the p53 target genes BAX, PERP, and p21 are also elevated in Del/Del tumors. However, opposite to MDM2, this association with rs150550023 genotype was restricted to TP53 wildtype tumors. Hence, it is most likely mediated by 
p53. (iii) Interestingly, p53 mRNA levels were also $\approx 3.5$-fold elevated in Del/Del vs. Ins/Ins tumors with a wildtype TP53, but not with a mutated TP53. However, this upregulation of p53 mRNA is not accompanied by an upregulation of p53 protein. Thus, Del/Del tumors appear to require higher levels of p53 mRNA to attain comparable levels of p53 protein. (iv) The levels of MDM2 mRNA, p53 mRNA, and p53 protein in Del/Del tumors are in a narrower range than in Ins/Ins tumors. (v) A positive correlation of MDM2 and ER mRNA levels was found in Ins/Ins, but not in Del/Del tumors. Moreover, MDM2 levels were significantly higher in ER positive vs. negative tumors with the Ins/Ins, but not the Del/Del genotype, indicating that this key activator of the MDM2 promoter P2 had a more modest effect on MDM2 expression in Del/Del tumors. (vi) Ins/Del tumors exhibited levels intermediate between Ins/Ins and Del/Del tumors for most parameters analyzed. Collectively, these findings indicate that the p53-MDM2 regulatory hub is strengthened and regulated more tightly in Del/Del tumors. This may make MDM2 expression levels more robust towards effects of other regulators such as the ER; and lead to a narrower, more tightly controlled range of the levels of MDM2 and p53. Of note, amplification of the MDM2 gene typically leads to much more than twofold upregulation of MDM2 expression [9], and the compensatory mechanisms observed here are unlikely to be effective.

The higher levels of MDM2 mRNA in Del/Del tumors are consistent with our JASPAR analysis, which predicted extra binding sites in the Ins allele for the transcriptional repressors FOXP1, E2F6, ZNF263, and ZNF384 [52-54,56,70,71]. Although the transcriptional activators FOXA1 and KLF5 [51,55] also have predicted additional binding sites in the Ins allele, they both bind to the minus-strand of MDM2 promoter P1 and exhibit rather modest JASPAR binding scores. Reporter assays upon transient transfection with a fragment of $M D M 2$ promoter $\mathrm{P} 1$ containing rs 150550023 have shown a $\approx 2$-fold higher promoter activity associated with the Ins-allele in HeLa, HepG2, and JEG-3 cell lines [15]. However, the effect attributed to rs 150550023 in these reporter assays may actually be due to SNP rs937282 located $\approx 1000 \mathrm{bp}$ downstream of rs150550023 [15,34]. Moreover, this study used an experimental system quite different from our quantification of endogenous MDM2 mRNA in $\approx 100$ human breast tumors, and included neither breast epithelial nor breast cancer cells, nor MDM2 promoter P2 with its potential modifying effects on MDM2 expression. The consequences of perturbations of the MDM2-p53 signaling hub appear to be quite different in ectoderm-, mesoderm-, and endoderm-derived cell types [3,72], and analyses of additional experimental systems and cell/tissue types may well be essential to arrive at a more complete picture of the functional impact of the rs150550023 Indel polymorphism.

\section{Materials and Methods}

\subsection{Study Population}

This study was approved by the Institutional Review Board (IRB; "Ethikkommission") of the Medical University of Vienna, Austria (MUV; protocol 141/2002), and is annually reviewed. Only women of Central European descent from the same geographical area were included in this study. Healthy females and consecutive patients with benign gynecological lesions without any malignancies (breast or other cancer) in their personal history were enrolled as nested controls between 2002 and 2004 at the Department of Obstetrics and Gynecology, MUV $(n=255)$. A total of 276 consecutive female breast cancer patients treated between 2002 and 2004, and another 134 consecutive patients treated between 1991 and 1994 at the Department of Obstetrics and Gynecology, MUV, were enrolled in this study. From the latter 134 patients, detailed follow-up records as well as fresh-frozen tumor tissue were available. Malignant breast cancer of all patients was confirmed by histopathology. Table S1 depicts the clinical and histopathological characteristics of the study population. Written informed consent was obtained from all participants enrolled between 2002 and 2004. The patients treated between 1991 and 1994 were enrolled retrospectively, and the IRB approved a waiver of specific informed consent for those patients. Three patients and one control subject were excluded from further analyses due to technical genotyping failure. Accordingly, all analyses shown are based on the 407 breast cancer patients and 254 controls for whom genotyping was successful. 


\subsection{Cell Lines}

Untransformed HMEC (human mammary epithelial cells) were kindly provided by M. R. Stampfer and grown in MEGM medium [73]. All other cell lines were purchased from DSMZ ("Deutsche Sammlung von Mikro-Organismen und Zellkulturen", Braunschweig, Germany): Cal51, HCC-1143, HCC-1937 and Kpl-1, or ATCC (American Type Culture Collection, Manassas, USA): AU565, BT474, Cama1, Hs578T, Hs578Bst, MCF7, MCF10A, MCF10F, MDA-MB-231, MDA-MB-435, MDA-MB-453, MDA-MB-468, SK-BR-3, T47D, and ZR75-1, and were cultured as described [74]. DSMZ and ATCC authenticate all cell lines by STR profiling and other methods before distribution. Genomic DNA and total RNA were isolated from all cell lines within three to eight passages after receipt as described [74,75].

\subsection{In Silico Analyses}

In silico analyses of putative transcription factor binding sites around the rs 150550023 site were performed using the JASPAR database [48] available from http://jaspar.genereg.net/ with default settings. Accordingly, only transcription factors with a relative binding score of $\geq 0.8$ were considered further. Those transcription factors were subjected to in silico expression analysis using The Human Protein Atlas [49] available from http://www.proteinatlas.org, and all transcription factors not expressed in breast tissue were omitted from further analysis. Finally, only those transcription factors with a differential binding between the Ins- vs. the Del-allele (i.e., a different number of binding sites and/or different relative binding scores) were included in the final result and visualized in Figure 1c. The JASPAR analysis was repeated with CIS-BP, an independent database available from http: //cisbp.ccbr.utoronto.ca/ with default settings. i.e., a threshold of $\geq 8$ for the binding score.

\subsection{DNA Isolation and Genotyping}

All samples were genotyped by using genomic DNA extracted from peripheral lymphocytes with the QIAamp DNA Blood Midi kit (Qiagen, Venlo, The Netherlands), and from fresh-frozen tumor tissue with the High Pure PCR Template Preparation Kit (Roche, Vienna, Austria) as described [66,76]. SNP rs150550023 (rs3730485; del1518) in promoter P1 of the MDM2 gene was genotyped by conventional PCR. Reactions contained 40 ng of genomic DNA, RedTaq PCR reaction mix (Sigma-Aldrich, Vienna, Austria) and a primer pair described in [32] in a reaction volume of $25 \mu \mathrm{L}$. PCR products were analyzed by gel electrophoresis with $2 \%$ agarose gels. The Ins-allele gave rise to a $287 \mathrm{bp}$ PCR product, and the Del-allele to a 247bp PCR product [32]. The following quality control measures were followed: (i) $\approx 200$ samples were genotyped in duplicate, including five samples from separate DNA isolations; (ii) 45 samples were re-genotyped with a different primer pair described in [15]; (iii) genotypes of four samples (one patient and one control each with genotypes Ins/Ins and Del/Del) were confirmed by Sanger sequencing of PCR-products, after purification with the M-pure kit (Analytik Jena, Vienna, Austria; Figure 1a). (iv) Sizes of PCR products with both primer pairs were verified for six samples with a Bioanalyzer 2100 and a DNA 1000 Nano LabChip kit (Agilent, St. Clara, CA, USA) to be exactly as predicted from the corresponding sequence retrieved from NCBI variation viewer assembly GRCh38.p12, demonstrating that PCR-products observed are specific; (v) laboratory staff was blinded regarding patient or control status and identity of duplicates; (vi) genotypes were independently scored by three authors based on agarose gel results, and results consolidated by consensus. Genotyping failed for three patients and one control due to poor quality of genomic DNA. All samples were previously genotyped for MDM2 SNP309 (rs2279744) as described [21].

\section{5. qRT-PCR Analysis of $m R N A$ Expression Levels}

Isolation of total RNA from 111 fresh-frozen tumor samples with TRIreagent (Sigma, Vienna, Austria), quality control of the isolated RNA with the Bioanalyzer 2100 (Agilent, St. Clara, USA), reverse transcription with the High-Capacity cDNA Archive Kit (Applied Biosystems, Brunn/Gebirge, Austria), and quantification of relative mRNA levels of $M D M 2, \mathrm{p} 53, B A X, P E R P$, and $\mathrm{p} 21$ has been described 
previously [66,77]. Briefly, each sample was analyzed in duplicate by a quantitative reverse transcription PCR (qRT-PCR; real-time PCR) with an Applied Biosystems 7500 fast instrument, using the following primers and gene-specific probes obtained from Applied Biosystems: MDM2, hs00234753_m1; p53, hs_001533340_m1; BAX, hs00414514_m1; PERP, hs00953482_g1; p21, hs00355782_m1; and $\beta$-actin (control), hs_99999903_m1. In each qRT-PCR run, two to four negative controls $(2.5 \mu \mathrm{L}$ ddH2O instead of cDNA) were included and run in parallel. No signal was obtained in any of these reactions. As a positive control, duplicate samples of serial dilutions of a cDNA standard (cultured normal breast epithelial cells; HMECs) were included in each run. The mRNA levels of MDM2, p53, BAX, PERP, and p21 were normalized to those of $\beta$-actin in each sample (producing $\triangle \mathrm{Ct}$ values), and were further normalized by expressing the levels of all tumor samples relative to those of four control samples of normal breast tissue (producing $\Delta \Delta \mathrm{Ct}$ values). Four non-cancer cell lines were used as normalization controls for the analyses in breast cancer cell lines (HMEC, Hs578Bst, MCF10A, and MCF10F; indicated as open circles in Figure 4). All relative mRNA expression levels are presented as $2^{-\Delta \Delta C t}$ values (i.e., as linear values, but on a logarithmic ordinate) as described [66,77].

\subsection{Statistical Analyses}

Statistical analyses were performed with R 3.3.2, an open-source language and environment for statistical computing available from www.r-project.org [78]. Hardy-Weinberg equilibrium was evaluated by chi-square tests with Yates' continuity correction. Confidence intervals and $p$-values associated with odds ratios were calculated by the mid-P exact method. We consider our subgroup analyses (Figure 2) as exploratory, and therefore we did not adjust for multiple testing, in agreement with previous recommendations [79]. $p$-values for the cumulative breast cancer incidence were determined by log-rank tests as described [80]. Differences with respect to age at onset, mRNA levels, and numbers (\%) of p53 positive cells between two groups were analyzed with unpaired, two-sided $t$-tests, and between three groups with ANOVA. Correlations between expression levels of two genes were analyzed by determining Spearman's rank correlation coefficients $(\mathrm{rho} / \rho / \mathrm{r})$ and corresponding $p$-values. Follow-up details of our study population have been described $[66,77]$. The overall and metastasis-free survival was analyzed by univariable and multivariable Cox proportional hazard models, and included the variables rs150550023 genotype, SNP309 genotype, TP53 status, ER status, and PR status. The subcategories of these variables were coded as follows: rs 150550023 genotype, Ins/Ins = 0, Ins/Del = 1, Del/Del = 2; SNP309 genotype, TT = 0, TG = 1, GG = 2; ER and PR status, positive $=0$, negative $=1$; TP53 status, wildtype $=0$, mutated $=1$ (determined by sequencing; Appendix A). All $p$-values shown are two-sided. Associations with $p$-values $<0.05$ were considered statistically significant.

\section{Conclusions}

The results of our expression analyses are consistent with a model in which the p53-MDM2 regulatory hub is strengthened and regulated more tightly in Del/Del tumors, making it more robust towards effects by other regulators of this hub such as the ER; leading to a narrower, more tightly controlled range of the levels of MDM2 and p53. This new set-point of the p53-MDM2 regulatory loop with a higher basal activity in Del/Del is likely initiated by a higher transcriptional activity of MDM2 promoter P1 harboring the Del-allele. These higher MDM2 levels may then lead to a compensatory upregulation of p53 mRNA, likely executed by the multiple feedback loops which regulate p53 mRNA transcription, stability, and translation efficiency. Among others, these regulatory feedback loops involve binding of p53 to its own promoter, and binding of p53, MDM2, and the p53 target gene WIG1 to p53 mRNA [12,67,81]. The higher basal levels of both p53 and MDM2 mRNA presumably neutralize each other, leading to a higher rate of both synthesis and degradation of p53 protein in the absence of stress. This may explain why the higher levels of p53 mRNA do not lead to higher p53 protein levels, which is important since basal p53 protein levels must be neither too high nor too low. However, the higher basal p53 mRNA levels may set the stage for a more potent p53 stress response 
with a higher amplitude and longer sustainability [81]. Indeed, p53 mRNA levels may be a limiting factor for p53 protein levels in Ins/Ins, but not Del/Del tumors, indicated by a positive correlation in the former, but not the latter. The equally higher MDM2 levels in Del/Del become irrelevant in a stress response, since its negative regulation of p53 is rapidly inactivated, and MDM2 may even be turned into an activator of p53 [12]. However, we did not find clear phenotypic consequences of the proposed impact of rs150550023 genotype upon regulation of the p53-MDM2 hub with respect to cancer risk, age of onset, rate of TP53 mutation, or survival.

Supplementary Materials: The following are available online at http://www.mdpi.com/2072-6694/12/11/3363/s1: Table S1: Clinical characteristics and genotype frequencies of rs150550023 of the study population.

Author Contributions: Conceptualization, M.S.; methodology, H.M.; B.D. and K.K.; validation, M.S.; H.M.; B.D. and K.K.; formal analysis, M.S.; investigation, H.M. and B.D.; resources, M.S. and K.K.; data curation, H.M. and M.S.; writing-original draft preparation, M.S.; writing-review and editing, M.S.; H.M.; B.D. and K.K.; visualization, H.M. and M.S.; supervision, H.M. and M.S.; project administration, H.M.; funding acquisition, M.S. All authors have read and agreed to the published version of the manuscript.

Funding: This research was supported by funds of the "Oesterreichische Nationalbank" (Anniversary Fund, project number: 12994).

Acknowledgments: We thank Martha R. Stampfer, Lawrence Berkeley National Laboratory, Berkeley, California, for kindly providing HMEC cells, and Birgit Schmölzer for critical review of the manuscript.

Conflicts of Interest: The authors declare no conflict of interest. The funders had no role in the design of the study; in the collection, analyses, or interpretation of data; in the writing of the manuscript, or in the decision to publish the results.

\section{Appendix A}

P53 status was determined as follows (detailed results will be reported elsewhere): for the patients enrolled between 2002 and 2004, p53 status had been determined by immune histochemistry (IHC) as part of the routine clinical management in Austrian hospitals, and was retrieved from their clinical records. The presence of $\geq 10 \%$ p53-positive tumor cell nuclei was scored as "p53 positive" in this routine clinical diagnosis, in agreement with national and international guidelines. P53 positivity in IHC is considered as indication of an inactivating mutation of TP53, which leads to a defective p53-MDM2 negative feedback loop and hence stabilization and accumulation of the mutated p53 protein [61,82-85]. For the patients treated between 1991 and 1994, the determination of p53 status was not yet part of their routine clinical management. Accordingly, we determined the p53 status for 105 of these patients retrospectively following IHC procedures of current routine diagnosis. Tissue microarrays with triplicate tumor tissue samples of these patients [86] were stained with monoclonal anti-p53 antibody (clone DO-7, Dako/Agilent, St. Clara, USA) at a dilution of 1:800 for one hour. In addition, TP53 status was determined by sequencing of genomic DNA isolated from fresh-frozen, native tumor tissue of 127 of the patients treated between 1991 and 1994. A total of 116 patients were analyzed by Sanger sequencing of TP53 exon 4-9 from both directions as described [66]. In addition, the complete TP53 coding sequence of 78 patients was analyzed by ultra-deep sequencing (average sequencing depth of the TP53 gene, 15,494 \pm 12,434) with the TruSight Tumor 26 (TS26) gene panel on a MySeq instrument (Illumina, San Diego, USA). In total, 67 of those patients had previously been analyzed by Sanger sequencing, and initial discordant results $(n=10$, mostly with $<15 \%$ variant reads) were resolved by re-evaluating the original Sanger sequence chromatograms, and by repeating the Sanger sequencing. Altogether, the TP53 sequence of 127 patients was successfully ascertained, 49 by Sanger sequencing only, 11 with targeted next-generation sequencing only, and 67 with both methods. Sequence variants detected in the TP53 coding sequence were scored as TP53 mutations, with the exception of (i) germline polymorphisms such as R72P (rs1042522); (ii) silent (synonymous) point mutations; (iii) variants detected in $<10 \%$ of the Illumina reads; (iv) variants scored as benign or likely benign according to the IARC TP53 database at https://p53.iarc.fr/ or according to ACMG/AMP consensus guidelines [87]. 


\section{References}

1. Martincorena, I.; Campbell, P.J. Somatic mutation in cancer and normal cells. Science 2015, 349, $1483-1489$. [CrossRef] [PubMed]

2. Hainaut, P.; Pfeifer, G.P. Somatic TP53 Mutations in the Era of Genome Sequencing. Cold Spring Harb. Perspect. Med. 2016, 6. [CrossRef] [PubMed]

3. Levine, A.J. p53: 800 million years of evolution and 40 years of discovery. Nat. Rev. Cancer 2020, 20, 471-480. [CrossRef] [PubMed]

4. Kastenhuber, E.R.; Lowe, S.W. Putting p53 in Context. Cell 2017, 170, 1062-1078. [CrossRef] [PubMed]

5. Bieging, K.T.; Mello, S.S.; Attardi, L.D. Unravelling mechanisms of p53-mediated tumour suppression. Nat. Rev. Cancer 2014, 14, 359-370. [CrossRef] [PubMed]

6. Kruiswijk, F.; Labuschagne, C.F.; Vousden, K.H. p53 in survival, death and metabolic health: A lifeguard with a licence to kill. Nat. Rev. Mol. Cell Biol. 2015, 16, 393-405. [CrossRef]

7. Aubrey, B.J.; Kelly, G.L.; Janic, A.; Herold, M.J.; Strasser, A. How does p53 induce apoptosis and how does this relate to p53-mediated tumour suppression? Cell Death Differ. 2018, 25, 104-113. [CrossRef]

8. $\quad$ Burgess, A.; Chia, K.M.; Haupt, S.; Thomas, D.; Haupt, Y.; Lim, E. Clinical Overview of MDM2/X-Targeted Therapies. Front. Oncol. 2016, 6, 7. [CrossRef]

9. Oliner, J.D.; Saiki, A.Y.; Caenepeel, S. The Role of MDM2 Amplification and Overexpression in Tumorigenesis. Cold Spring Harb. Perspect. Med. 2016, 6. [CrossRef]

10. Pant, V.; Lozano, G. Limiting the power of p53 through the ubiquitin proteasome pathway. Genes Dev. 2014, 28, 1739-1751. [CrossRef]

11. Wade, M.; Li, Y.C.; Wahl, G.M. MDM2, MDMX and p53 in oncogenesis and cancer therapy. Nat. Rev. Cancer 2013, 13, 83-96. [CrossRef] [PubMed]

12. Haronikova, L.; Olivares-Illana, V.; Wang, L.; Karakostis, K.; Chen, S.; Fahraeus, R. The p53 mRNA: An integral part of the cellular stress response. Nucleic Acids Res. 2019, 47, 3257-3271. [CrossRef] [PubMed]

13. Jones, S.N.; Roe, A.E.; Donehower, L.A.; Bradley, A. Rescue of embryonic lethality in Mdm2-deficient mice by absence of p53. Nature 1995, 378, 206-208. [CrossRef] [PubMed]

14. Montes de Oca Luna, R.; Wagner, D.S.; Lozano, G. Rescue of early embryonic lethality in mdm2-deficient mice by deletion of p53. Nature 1995, 378, 203-206. [CrossRef] [PubMed]

15. Lalonde, M.E.; Ouimet, M.; Lariviere, M.; Kritikou, E.A.; Sinnett, D. Identification of functional DNA variants in the constitutive promoter region of MDM2. Hum. Genom. 2012, 6. [CrossRef] [PubMed]

16. Oliner, J.D.; Pietenpol, J.A.; Thiagalingam, S.; Gyuris, J.; Kinzler, K.W.; Vogelstein, B. Oncoprotein MDM2 conceals the activation domain of tumour suppressor p53. Nature 1993, 362, 857-860. [CrossRef]

17. Acun, T.; Terzioglu-Kara, E.; Konu, O.; Ozturk, M.; Yakicier, M.C. Mdm2 Snp309 G allele displays high frequency and inverse correlation with somatic P53 mutations in hepatocellular carcinoma. Mutat Res. 2010, 684, 106-108. [CrossRef]

18. Bond, G.L.; Hu, W.; Bond, E.E.; Robins, H.; Lutzker, S.G.; Arva, N.C.; Bargonetti, J.; Bartel, F.; Taubert, H.; Wuerl, P.; et al. A single nucleotide polymorphism in the MDM2 promoter attenuates the p53 tumor suppressor pathway and accelerates tumor formation in humans. Cell 2004, 119, 591-602. [CrossRef]

19. Deben, C.; Op de Beeck, K.; Van den Bossche, J.; Jacobs, J.; Lardon, F.; Wouters, A.; Peeters, M.; Van Camp, G.; Rolfo, C.; Deschoolmeester, V.; et al. MDM2 SNP309 and SNP285 Act as Negative Prognostic Markers for Non-small Cell Lung Cancer Adenocarcinoma Patients. J. Cancer 2017, 8, 2154-2162. [CrossRef]

20. Hu, W.; Feng, Z.; Ma, L.; Wagner, J.; Rice, J.J.; Stolovitzky, G.; Levine, A.J. A single nucleotide polymorphism in the MDM2 gene disrupts the oscillation of p53 and MDM2 levels in cells. Cancer Res. 2007, 67, 2757-2765. [CrossRef]

21. Miedl, H.; Lebhard, J.; Ehart, L.; Schreiber, M. Association of the MDM2 SNP285 and SNP309 Genetic Variants with the Risk, Age at Onset and Prognosis of Breast Cancer in Central European Women: A Hospital-Based Case-Control Study. Int. J. Mol. Sci. 2019, 20, 509. [CrossRef]

22. Post, S.M.; Quintas-Cardama, A.; Pant, V.; Iwakuma, T.; Hamir, A.; Jackson, J.G.; Maccio, D.R.; Bond, G.L.; Johnson, D.G.; Levine, A.J.; et al. A high-frequency regulatory polymorphism in the p53 pathway accelerates tumor development. Cancer Cell 2010, 18, 220-230. [CrossRef] 
23. Sanchez-Carbayo, M.; Socci, N.D.; Kirchoff, T.; Erill, N.; Offit, K.; Bochner, B.H.; Cordon-Cardo, C. A polymorphism in HDM2 (SNP309) associates with early onset in superficial tumors, TP53 mutations, and poor outcome in invasive bladder cancer. Clin. Cancer Res. 2007, 13, 3215-3220. [CrossRef]

24. Economopoulos, K.P.; Sergentanis, T.N. Differential effects of MDM2 SNP309 polymorphism on breast cancer risk along with race: A meta-analysis. Breast Cancer Res. Treat. 2010, 120, 211-216. [CrossRef]

25. Hu, Z.; Jin, G.; Wang, L.; Chen, F.; Wang, X.; Shen, H. MDM2 promoter polymorphism SNP309 contributes to tumor susceptibility: Evidence from 21 case-control studies. Cancer Epidemiol. Biomark. Prev. 2007, 16, 2717-2723.

26. Zhao, E.; Cui, D.; Yuan, L.; Lu, W. MDM2 SNP309 polymorphism and breast cancer risk: A meta-analysis. Mol. Biol Rep. 2012, 39, 3471-3477. [CrossRef]

27. Hua, W.; Zhang, A.; Duan, P.; Zhu, J.; Zhao, Y.; He, J.; Zhang, Z. MDM2 promoter del1518 polymorphism and cancer risk: Evidence from 22,931 subjects. Onco. Targets Ther. 2017, 10, 3773-3780. [CrossRef]

28. Yu, H.; Li, H.; Zhang, J.; Liu, G. Influence of MDM2 polymorphisms on squamous cell carcinoma susceptibility: A meta-analysis. Onco. Targets Ther. 2016, 9, 6211-6224. [CrossRef]

29. Moazeni-Roodi, A.; Ghavami, S.; Hashemi, M. The 40bp indel polymorphism of MDM2 increase the risk of cancer: An updated meta-analysis. Mol. Biol. Res. Commun. 2019, 8, 1-8.

30. Gansmo, L.B.; Vatten, L.; Romundstad, P.; Hveem, K.; Ryan, B.M.; Harris, C.C.; Knappskog, S.; Lonning, P.E. Associations between the MDM2 promoter P1 polymorphism del1518 (rs3730485) and incidence of cancer of the breast, lung, colon and prostate. Oncotarget 2016, 7, 28637-28646. [CrossRef]

31. Ma, H.; Hu, Z.; Zhai, X.; Wang, S.; Wang, X.; Qin, J.; Jin, G.; Liu, J.; Wang, X.; Wei, Q.; et al. Polymorphisms in the MDM2 promoter and risk of breast cancer: A case-control analysis in a Chinese population. Cancer Lett. 2006, 240, 261-267. [CrossRef]

32. Hashemi, M.; Omrani, M.; Eskandari-Nasab, E.; Hasani, S.S.; Mashhadi, M.A.; Taheri, M. A 40-bp insertion/deletion polymorphism of Murine Double Minute2 (MDM2) increased the risk of breast cancer in Zahedan, Southeast Iran. Iran. Biomed. J. 2014, 18, 245-249.

33. Gallegos-Arreola, M.P.; Marquez-Rosales, M.G.; Sanchez-Corona, J.; Figuera, L.E.; Zuniga-Gonzalez, G.; Puebla-Perez, A.M.; Delgado-Saucedo, J.I.; Montoya-Fuentes, H. Association of the Del1518 Promoter (rs3730485) Polymorphism in the MDM2 Gene with Breast Cancer in a Mexican Population. Ann. Clin. Lab. Sci. 2017, 47, 291-297.

34. Wang, M.; Zhang, Z.; Zhu, H.; Fu, G.; Wang, S.; Wu, D.; Zhou, J.; Wei, Q.; Zhang, Z. A novel functional polymorphism C1797G in the MDM2 promoter is associated with risk of bladder cancer in a Chinese population. Clin. Cancer Res. 2008, 14, 3633-3640. [CrossRef]

35. Hu, Z.; Ma, H.; Lu, D.; Qian, J.; Zhou, J.; Chen, Y.; Xu, L.; Wang, X.; Wei, Q.; Shen, H. Genetic variants in the MDM2 promoter and lung cancer risk in a Chinese population. Int J. Cancer 2006, 118, 1275-1278. [CrossRef]

36. Tripon, F.; Iancu, M.; Trifa, A.; Crauciuc, G.A.; Boglis, A.; Balla, B.; Cosma, A.; Dima, D.; Candea, M.; Lazar, E.; et al. Association Analysis of TP53 rs1042522, MDM2 rs2279744, rs3730485, MDM4 rs4245739 Variants and Acute Myeloid Leukemia Susceptibility, Risk Stratification Scores, and Clinical Features: An Exploratory Study. J. Clin. Med. 2020, 9, 1672. [CrossRef]

37. Maruei-Milan, R.; Heidari, Z.; Salimi, S. Role of MDM2 309T>G (rs2279744) and I/D (rs3730485) polymorphisms and haplotypes in risk of papillary thyroid carcinoma, tumor stage, tumor size, and early onset of tumor: A case control study. J. Cell Physiol. 2019, 234, 12934-12940. [CrossRef]

38. Gansmo, L.B.; Bjornslett, M.; Halle, M.K.; Salvesen, H.B.; Romundstad, P.; Hveem, K.; Vatten, L.; Dorum, A.; Lonning, P.E.; Knappskog, S. MDM2 promoter polymorphism del1518 (rs3730485) and its impact on endometrial and ovarian cancer risk. BMC Cancer 2017, 17, 97. [CrossRef]

39. Dong, D.; Gao, X.; Zhu, Z.; Yu, Q.; Bian, S.; Gao, Y. A 40-bp insertion/deletion polymorphism in the constitutive promoter of MDM2 confers risk for hepatocellular carcinoma in a Chinese population. Gene 2012, 497, 66-70. [CrossRef]

40. Cavalcante, G.C.; Amador, M.A.; Ribeiro Dos Santos, A.M.; Carvalho, D.C.; Andrade, R.B.; Pereira, E.E.; Fernandes, M.R.; Costa, D.F.; Santos, N.P.; Assumpcao, P.P.; et al. Analysis of 12 variants in the development of gastric and colorectal cancers. World J. Gastroenterol. 2017, 23, 8533-8543. [CrossRef]

41. Zhang, L.; Zhu, Z.D.; Wu, H.Y.; Wang, K.J. Association between SNP309 and del 1518 Polymorphism in MDM2 Homologue and Esophageal Squamous Cell Carcinoma Risk in Chinese Population of Shandong Province. Ann. Clin. Lab. Sci. 2015, 45, 433-437. 
42. Hashemi, M.; Amininia, S.; Ebrahimi, M.; Simforoosh, N.; Basiri, A.; Ziaee, S.A.M.; Narouie, B.; Sotoudeh, M.; Mollakouchekian, M.J.; Rezghi Maleki, E.; et al. Association between polymorphisms in TP53 and MDM2 genes and susceptibility to prostate cancer. Oncol. Lett. 2017, 13, 2483-2489. [CrossRef]

43. Salimi, S.; Hajizadeh, A.; Khodamian, M.; Pejman, A.; Fazeli, K.; Yaghmaei, M. Age-dependent association of MDM2 promoter polymorphisms and uterine leiomyoma in South-East Iran: A preliminary report. J. Obstet. Gynaecol. Res. 2015, 41, 729-734. [CrossRef]

44. Maleki, Y.; Alahbakhshi, Z.; Heidari, Z.; Moradi, M.T.; Rahimi, Z.; Yari, K.; Rahimi, Z.; Aznab, M.; Ahmadi-Khajevand, M.; Bahremand, F. NOTCH1, SF3B1, MDM2 and MYD88 mutations in patients with chronic lymphocytic leukemia. Oncol. Lett. 2019, 17, 4016-4023. [CrossRef]

45. Ma, J.; Zhang, J.; Ning, T.; Chen, Z.; Xu, C. Association of genetic polymorphisms in MDM2, PTEN and P53 with risk of esophageal squamous cell carcinoma. J. Hum. Genet. 2012, 57, 261-264. [CrossRef]

46. Kang, S.; Wang, D.J.; Li, W.S.; Wang, N.; Zhou, R.M.; Sun, D.L.; Duan, Y.N.; Li, S.Z.; Li, X.F.; Li, Y. Association of p73 and MDM2 polymorphisms with the risk of epithelial ovarian cancer in Chinese women. Int. J. Gynecol. Cancer 2009, 19, 572-577. [CrossRef]

47. Hashemi, M.; Naderi, M.; Eskandari Nasab, E.; Hasani, S.S.; Sadeghi Bojd, S.; Taheri, M. Evaluation of 40-bp Insertion/Deletion Polymorphism of MDM2 and the Risk of Childhood Acute Lymphoblastic Leukemia. Gene. Cell. Tissue 2015, 2, e26974. [CrossRef]

48. Fornes, O.; Castro-Mondragon, J.A.; Khan, A.; van der Lee, R.; Zhang, X.; Richmond, P.A.; Modi, B.P.; Correard, S.; Gheorghe, M.; Baranasic, D.; et al. JASPAR 2020: Update of the open-access database of transcription factor binding profiles. Nucleic Acids Res. 2020, 48, D87-D92. [CrossRef]

49. Uhlen, M.; Fagerberg, L.; Hallstrom, B.M.; Lindskog, C.; Oksvold, P.; Mardinoglu, A.; Sivertsson, A.; Kampf, C.; Sjostedt, E.; Asplund, A.; et al. Proteomics. Tissue-based map of the human proteome. Science 2015, 347, 1260419. [CrossRef]

50. Weirauch, M.T.; Yang, A.; Albu, M.; Cote, A.G.; Montenegro-Montero, A.; Drewe, P.; Najafabadi, H.S.; Lambert, S.A.; Mann, I.; Cook, K.; et al. Determination and inference of eukaryotic transcription factor sequence specificity. Cell 2014, 158, 1431-1443. [CrossRef]

51. Bernardo, G.M.; Keri, R.A. FOXA1: A transcription factor with parallel functions in development and cancer. Biosci. Rep. 2012, 32, 113-130. [CrossRef] [PubMed]

52. Jepsen, K.; Gleiberman, A.S.; Shi, C.; Simon, D.I.; Rosenfeld, M.G. Cooperative regulation in development by SMRT and FOXP1. Genes Dev. 2008, 22, 740-745. [CrossRef] [PubMed]

53. Morinobu, M.; Nakamoto, T.; Hino, K.; Tsuji, K.; Shen, Z.J.; Nakashima, K.; Nifuji, A.; Yamamoto, H.; Hirai, H.; Noda, M. The nucleocytoplasmic shuttling protein CIZ reduces adult bone mass by inhibiting bone morphogenetic protein-induced bone formation. J. Exp. Med. 2005, 201, 961-970. [CrossRef] [PubMed]

54. Trimarchi, J.M.; Fairchild, B.; Verona, R.; Moberg, K.; Andon, N.; Lees, J.A. E2F-6, a member of the E2F family that can behave as a transcriptional repressor. Proc. Natl. Acad. Sci. USA 1998, 95, 2850-2855. [CrossRef]

55. Liu, R.; Dong, J.T.; Chen, C. Role of KLF5 in hormonal signaling and breast cancer development. Vitam. Horm. 2013, 93, 213-225.

56. Frietze, S.; Lan, X.; Jin, V.X.; Farnham, P.J. Genomic targets of the KRAB and SCAN domain-containing zinc finger protein 263. J. Biol. Chem. 2010, 285, 1393-1403. [CrossRef]

57. Karczewski, K.J.; Francioli, L.C.; Tiao, G.; Cummings, B.B.; Alföldi, J.; Wang, Q.; Collins, R.L.; Laricchia, K.M.; Ganna, A.; Birnbaum, D.P.; et al. The mutational constraint spectrum quantified from variation in 141,456 humans. Nature 2020, 581, 434-443. [CrossRef]

58. Bond, G.L.; Hirshfield, K.M.; Kirchhoff, T.; Alexe, G.; Bond, E.E.; Robins, H.; Bartel, F.; Taubert, H.; Wuerl, P.; Hait, W.; et al. MDM2 SNP309 accelerates tumor formation in a gender-specific and hormone-dependent manner. Cancer Res. 2006, 66, 5104-5110. [CrossRef]

59. Bond, G.L.; Levine, A.J. A single nucleotide polymorphism in the p53 pathway interacts with gender, environmental stresses and tumor genetics to influence cancer in humans. Oncogene 2007, 26, 1317-1323. [CrossRef]

60. Lum, S.S.; Chua, H.W.; Li, H.; Li, W.F.; Rao, N.; Wei, J.; Shao, Z.; Sabapathy, K. MDM2 SNP309 G allele increases risk but the $\mathrm{T}$ allele is associated with earlier onset age of sporadic breast cancers in the Chinese population. Carcinogenesis 2008, 29, 754-761. [CrossRef]

61. Lacroix, M.; Toillon, R.A.; Leclercq, G. p53 and breast cancer, an update. Endocr. Relat. Cancer 2006, 13, 293-325. [CrossRef] [PubMed] 
62. Dusek, R.L.; Bascom, J.L.; Vogel, H.; Baron, S.; Borowsky, A.D.; Bissell, M.J.; Attardi, L.D. Deficiency of the p53/p63 target Perp alters mammary gland homeostasis and promotes cancer. Breast Cancer Res. 2012, 14, R65. [CrossRef]

63. El-Deiry, W.S. p21(WAF1) Mediates Cell-Cycle Inhibition, Relevant to Cancer Suppression and Therapy. Cancer Res. 2016, 76, 5189-5191. [CrossRef] [PubMed]

64. Ho, T.; Tan, B.X.; Lane, D. How the Other Half Lives: What p53 Does When It Is Not Being a Transcription Factor. Int. J. Mol. Sci. 2019, 21, 13. [CrossRef] [PubMed]

65. Jeong, B.S.; Hu, W.; Belyi, V.; Rabadan, R.; Levine, A.J. Differential levels of transcription of p53-regulated genes by the arginine/proline polymorphism: p53 with arginine at codon 72 favors apoptosis. Faseb. J. 2010, 24, 1347-1353. [CrossRef] [PubMed]

66. Proestling, K.; Hebar, A.; Pruckner, N.; Marton, E.; Vinatzer, U.; Schreiber, M. The Pro Allele of the p53 Codon 72 Polymorphism Is Associated with Decreased Intratumoral Expression of BAX and p21, and Increased Breast Cancer Risk. PLoS ONE 2012, 7, e47325. [CrossRef] [PubMed]

67. Wang, S.; El-Deiry, W.S. p73 or p53 directly regulates human p53 transcription to maintain cell cycle checkpoints. Cancer Res. 2006, 66, 6982-6989. [CrossRef]

68. Brekman, A.; Singh, K.E.; Polotskaia, A.; Kundu, N.; Bargonetti, J. A p53-independent role of Mdm2 in estrogen-mediated activation of breast cancer cell proliferation. Breast Cancer Res. 2011, 13, R3. [CrossRef]

69. Swetzig, W.M.; Wang, J.; Das, G.M. Estrogen receptor alpha (ERalpha/ESR1) mediates the p53-independent overexpression of MDM4/MDMX and MDM2 in human breast cancer. Oncotarget 2016, 7, 16049-16069. [CrossRef]

70. Shen, Z.J.; Nakamoto, T.; Tsuji, K.; Nifuji, A.; Miyazono, K.; Komori, T.; Hirai, H.; Noda, M. Negative regulation of bone morphogenetic protein/Smad signaling by Cas-interacting zinc finger protein in osteoblasts. J. Biol. Chem. 2002, 277, 29840-29846. [CrossRef]

71. Jen, J.; Lin, L.L.; Chen, H.T.; Liao, S.Y.; Lo, F.Y.; Tang, Y.A.; Su, W.C.; Salgia, R.; Hsu, C.L.; Huang, H.C.; et al. Oncoprotein ZNF322A transcriptionally deregulates alpha-adducin, cyclin D1 and p53 to promote tumor growth and metastasis in lung cancer. Oncogene 2016, 35, 2357-2369. [CrossRef] [PubMed]

72. McGowan, E.M.; Lin, Y.; Hatoum, D. Good Guy or Bad Guy? The Duality of Wild-Type p53 in Hormone-Dependent Breast Cancer Origin, Treatment, and Recurrence. Cancers 2018, 10, 172. [CrossRef] [PubMed]

73. Stampfer, M.R.; Bartley, J.C. Human mammary epithelial cells in culture: Differentiation and transformation. Cancer Treat. Res. 1988, 40, 1-24. [PubMed]

74. Pacher, M.; Seewald, M.J.; Mikula, M.; Oehler, S.; Mogg, M.; Vinatzer, U.; Eger, A.; Schweifer, N.; Varecka, R.; Sommergruber, W.; et al. Impact of constitutive IGF1/IGF2 stimulation on the transcriptional program of human breast cancer cells. Carcinogenesis 2007, 28, 49-59. [CrossRef] [PubMed]

75. Friesenhengst, A.; Pribitzer-Winner, T.; Schreiber, M. Association of the G473A Polymorphism and Expression of Lysyl Oxidase with Breast Cancer Risk and Survival in European Women: A Hospital-Based Case-Control Study. PLoS ONE 2014, 9, e105579. [CrossRef]

76. Taubenschuß, E.; Marton, E.; Mogg, M.; Frech, B.; Ehart, L.; Muin, D.; Schreiber, M. The L10P Polymorphism and Serum Levels of Transforming Growth Factor $\beta 1$ in Human Breast Cancer. Int. J. Mol. Sci. 2013, 14, 15376-15385. [CrossRef]

77. Friesenhengst, A.; Pribitzer-Winner, T.; Miedl, H.; Pröstling, K.; Schreiber, M. Elevated Aromatase (CYP19A1) Expression Is Associated with a Poor Survival of Patients with Estrogen Receptor Positive Breast Cancer. Horm. Cancer 2018, 9, 128-138. [CrossRef]

78. R Development Core Team. R: A Language and Environment for Statistical Computing; R Foundation for Statistical Computing: Vienna, Austria, 2009.

79. Bender, R.; Lange, S. Adjusting for multiple testing-when and how? J. Clin. Epidemiol. 2001, 54, $343-349$. [CrossRef]

80. Harrington, D.P.; Fleming, T.R. A Class of Rank Test Procedures for Censored Survival-Data. Biometrika 1982, 69, 553-566. [CrossRef]

81. Vilborg, A.; Wilhelm, M.T.; Wiman, K.G. Regulation of tumor suppressor p53 at the RNA level. J. Mol. Med. 2010, 88, 645-652. [CrossRef]

82. Borresen-Dale, A.L. TP53 and breast cancer. Hum. Mutat. 2003, 21, 292-300. [CrossRef] [PubMed] 
83. Kaserer, K.; Schmaus, J.; Bethge, U.; Migschitz, B.; Fasching, S.; Walch, A.; Herbst, F.; Teleky, B.; Wrba, F. Staining patterns of p53 immunohistochemistry and their biological significance in colorectal cancer. J. Pathol. 2000, 190, 450-456. [CrossRef]

84. Midgley, C.A.; Lane, D.P. p53 protein stability in tumour cells is not determined by mutation but is dependent on Mdm2 binding. Oncogene 1997, 15, 1179-1189. [CrossRef] [PubMed]

85. Norberg, T.; Lennerstrand, J.; Inganas, M.; Bergh, J. Comparison between p53 protein measurements using the luminometric immunoassay and immunohistochemistry with detection of p53 gene mutations using cDNA sequencing in human breast tumors. Int. J. Cancer 1998, 79, 376-383. [CrossRef]

86. Vinatzer, U.; Dampier, B.; Streubel, B.; Pacher, M.; Seewald, M.J.; Stratowa, C.; Kaserer, K.; Schreiber, M. Expression of HER2 and the coamplified genes GRB7 and MLN64 in human breast cancer: Quantitative real-time reverse transcription-PCR as a diagnostic alternative to immunohistochemistry and fluorescence in situ hybridization. Clin. Cancer Res. 2005, 11, 8348-8357. [CrossRef] [PubMed]

87. Schreiber, M. More is not always better: Clinical genetics of familial breast cancer in the era of massively enhanced sequencing capacities. Transl. Cancer Res. 2016, 2016, S387-S391. [CrossRef]

Publisher's Note: MDPI stays neutral with regard to jurisdictional claims in published maps and institutional affiliations.

(C) 2020 by the authors. Licensee MDPI, Basel, Switzerland. This article is an open access article distributed under the terms and conditions of the Creative Commons Attribution (CC BY) license (http://creativecommons.org/licenses/by/4.0/). 